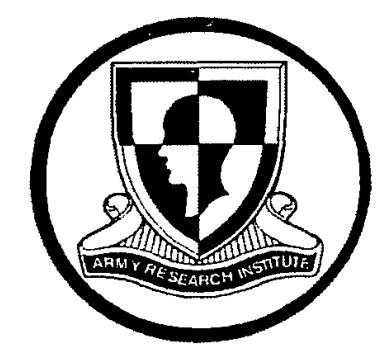

\author{
U.S. Army Research Institute \\ for the Behavioral and Social Sciences
}

Research Report 1810

\title{
Exploiting FBCB2 Capabilities Through Realistic Feedback
}

\author{
Bruce C. Leibrecht \\ Karen J. Lockaby \\ Northrup Grumman Mission Systems \\ Larry L. Meliza \\ U.S. Army Research Institute
}

July 2003 


\title{
U.S. Army Research Institute for the Behavioral and Social Sciences
}

\author{
A Directorate of the U.S. Total Army Personnel Command
}

\section{ZITA M. SIMUTIS \\ Director}

\begin{abstract}
Research accomplished under contract
for the Department of the Army

Northrup Grumman Mission Systems

Technical review by

John W. Diem, III Corps G3 Battle Command Training Branch

James M. Kanzenbach, TRADOC Warrior-T
\end{abstract}

\section{NOTICES}

DISTRIBUTION: Primary distribution of this Research Report has been made by ARI. Please address correspondence concerning distribution of reports to: U.S. Army Research Institute for the Behavioral and Social Sciences, Attn: TAPC-ARI-PO, 5001 Eisenhower Ave., Alexandria, VA 22333-5600.

FINAL DISPOSITION: This Research Report may be destroyed when it is no longer needed. Please do not return it to the U.S. Army Research Institute for the Behavioral and Social Sciences.

NOTE: The findings in this Research Report are not to be construed as an official Department of the Army position, unless so designated by other authorized documents. 


\section{REPORT DOCUMENTATION PAGE}

\begin{tabular}{|c|l|}
\hline $\begin{array}{c}\text { 1. REPORT DATE (dd-mm-yy) } \\
\text { July } 2003\end{array}$ & $\begin{array}{l}\text { 2. REPORT TYPE } \\
\text { Final }\end{array}$ \\
\hline
\end{tabular}

4. TITLE AND SUBTITLE

Exploiting FBCB2 Capabilities Through Realistic Feedback

3. DATES COVERED (from. . . to)

Mar 02- May 03

5a. CONTRACT OR GRANT NUMBER

DASW01-99-D-0013 (DO 22)

5 b. PROGRAM ELEMENT NUMBER

20262785

6. AUTHOR(S)

Bruce C. Leibrecht, \& Karen J. Lockaby (Northrop Grumman Mission Systems); and Larry L. Meliza (U.S. Army Research Institute)

5c. PROJECT NUMBER

A790

5d. TASK NUMBER

234

5e. WORK UNIT NUMBER

C01

7. PERFORMING ORGANIZATION NAME(S) AND ADDRESS(ES)

8. PERFORMING ORGANIZATION REPORT NUMBER

Northrop Grumman Space

and Mission Systems

One Federal Park Drive

Fairfax, VA 22033-4411

Orlando, FL 32826

9. SPONSORING/MONITORING AGENCY NAME(S) AND ADDRESS(ES)

U.S. Army Research Institute for the Behavioral and Social

Sciences

5001 Eisenhower Avenue

Alexandria, VA 22333-5600

U.S. Army Research Institute for the Behavioral and Social Sciences

Simulator Systems Research Unit

12350 Research Parkway

12. DISTRIBUTION/AVAILABILITY STATEMENT

Approved for public release; distribution is unlimited.

13. SUPPLEMENTARY NOTES

Delivery Order Contracting Officer's Representative, Larry L. Meliza.

14. ABSTRACT (Maximum 200 words):

This report describes the development of a proficiency measurement architecture for the Force XXI Battle Command Brigade and Below (FBCB2). It first explores primary dimensions of FBCB2-enabled performance-high-priority system capabilities, user digital skills and tasks, and network management skills. It then examines key factors that influence digital performance, including echelon, mission phase, unit standing operating procedures, task difficulty, and common performance problems. Finally, it discusses measurement implications of digitization, a comprehensive framework for presenting observation guidelines, and implications for FBCB2-focused After Action Reviews (AAR). The collective findings establish a basic architecture for measuring high-payoff proficiency targets, enhancing performance feedback capabilities, and optimizing the benefits of digital training programs. Two practical tools will help leaders and trainers focus on FBCB2-enabled skills that contribute significantly to combat effectiveness. Key recommendations for expanding the architecture and knowledge base are included.

15. SUBJECT TERMS

Digitization

Performance Assessment

Digital Training

Digital User Skills

C4I Capabilities

First Digitized Division

FBCB2 Exploitation

Digital Proficiency

\begin{tabular}{|c|c|c|c|c|c|}
\hline \multicolumn{3}{|c|}{ 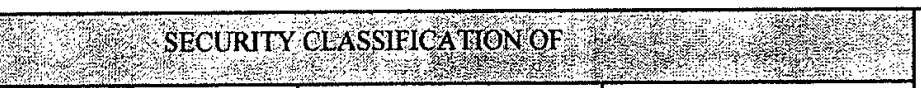 } & $\begin{array}{l}\text { 19. LIMITATION OF } \\
\text { ABSTRACT } \\
\text { Unlimited }\end{array}$ & $\begin{array}{l}\text { 20. NUMBER } \\
\text { OF PAGES } \\
53\end{array}$ & $\begin{array}{l}\text { 21. RESPONSIBLE PERSON } \\
\text { (Name and Telephone Number) } \\
\text { Dr. Larry Meliza } \\
\text { (407) 384-3992 }\end{array}$ \\
\hline
\end{tabular}




\title{
Exploiting FBCB2 Capabilities Through Realistic Feedback
}

\author{
Bruce C. Leibrecht \\ Karen J. Lockaby \\ Northrup Grumman Mission Systems \\ Larry L. Meliza \\ U.S. Army Research Institute
}
Simulator Systems Research Unit Stephen L. Goldberg, Chief

U.S. Army Research Institute for the Behavioral and Social Sciences 5001 Eisenhower Avenue, Alexandria, Virginia 22333-5600

July 2003 
Information age warfare challenges warfighters to exploit the powerful capabilities of advanced digital systems. In training to achieve digital proficiency, unit leaders and trainers need tools that help them focus on systems-enabled skills contributing significantly to tactical performance. In support of the digitized force, the U.S. Army Research Institute's Simulator Systems Research Unit (SSRU) investigates training and performance assessment needs. The SSRU assists III Corps' Battle Command Training Directorate and the Program Executive Office for Simulation, Training and Instrumentation (PEO-STRI) by developing performance measurement methods and tools for exploiting digital capabilities.

The goal of the research described in this report was to establish a basic proficiency measurement architecture for the Force XXI Battle Command Brigade and Below (FBCB2), the workhorse command and control system for platoons, companies, and battalions. The report explores primary dimensions of FBCB2-enabled performance, key factors influencing operator and user performance, and digital proficiency indicators with emphasis on observation and feedback guidelines. The findings establish a systematic framework for measuring high-payoff proficiency targets, enhancing performance feedback capabilities, and optimizing the benefits of digital training programs. A companion report presents two practical products-a Leader's Primer and an Exploitation Tool - that spotlight high-payoff measurement targets for FBCB2 operators and users.

Training developers and researchers can use the findings to focus training packages and tools on high-payoff proficiency targets. For training planners and managers, the proficiency measurement architecture can help enhance the training programs of FBCB2-enabled units-and ultimately their combat effectiveness. The authors' recommendations can constructively shape efforts to enhance training as a decisive force multiplier for the future operational environment.

The results of this work were briefed to III Corps' Battle Command Training Directorate at Fort Hood, Texas on 22 November 2002 and again on 29 January 2003.

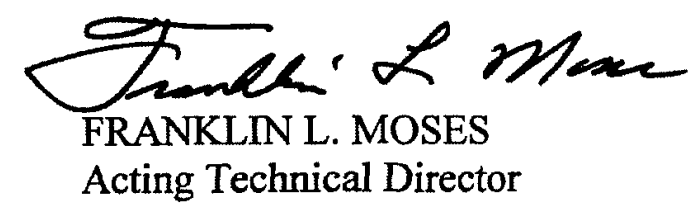


We thank the members of the $1^{\text {st }}$ and $2^{\text {nd }}$ Brigades, $4^{\text {th }}$ Infantry Division (4ID) (Mechanized) who generously participated in interview sessions. Equally important was the support of Mr. John Diem, III Corps Battle Command Training Directorate, and staff members of the Battle Command Training Center (BCTC). We are grateful to Kevin Harrison, Randall Hill, Marc Dudley, Chris Strauss, Conrad Hinkel, Alva Walker, and Jack Johnston of Northrop Grumman Mission Systems for their invaluable input as subject matter experts (SME). Ms. Wilma Sanders, also of Northrop Grumman Mission Systems, expertly supported editing and production of the report. 


\section{EXPLOITING FBCB2 CAPABILITIES THROUGH REALISTIC FEEDBACK}

\section{EXECUTIVE SUMMARY}

Research Requirement:

To realize the full benefits of information age warfighting technology, $21^{\text {st }}$ Century warriors need training that enables them to exploit digital capabilities. Such training requires a focus on high-priority digital tasks and skills, as well as criteria and procedures for measuring task and skill proficiency. At battalion echelon and below, the primary digital command and control system is the Force XXI Battle Command Brigade and Below (FBCB2). The Army has yet to establish FBCB2-based proficiency measurement standards and criteria in its emerging mission training plans for the digitized force. The overall goal of the current project was to develop a basic proficiency measurement architecture to enhance the efficiency and effectiveness of the assessment process in FBCB2-enabled collective training.

Procedure:

The research team leveraged the cumulative experience found in the Army's First Digitized Division (FDD), the $4^{\text {th }}$ Infantry Division (4ID) (Mechanized). Subject matter experts (SME) interviewed leaders and soldiers from the $1^{\text {st }}$ and $2^{\text {nd }}$ Brigade Combat Teams (BCT) of the division, and they also observed selective training exercises conducted by those units. The team analyzed the results to evaluate key variables and performance problems affecting FBCB2enabled operations. They further applied the results to develop indicators of digital proficiency, concentrating on observation guidelines and measurement/feedback implications. They also used the results, along with the expertise resident within the team, to develop user-friendly products defining high-payoff proficiency targets for FBCB2 operators and users.

Findings:

More than 20 high-priority FBCB2 capabilities were identified in the areas of operating basics, battlefield visualization, planning and preparation tools, information exchange, and force mobility/maneuver. The analytical process yielded nine high-priority user skills, each embracing up to ten specific FBCB2-driven tasks. Three major network management skills were identified, along with critical questions about network status. Among the key variables influencing digital performance were echelon, mission phase, unit standing operating procedures (SOP), task difficulty, and issues surrounding common performance problems. The matrix format for presenting observation guidelines conveyed who-what-when-where-why details to structure performance measurement activities. The ultimate value of much of the guideline information lies in focusing the After Action Review (AAR) process on utilizing FBCB2 capabilities.

Two practical products spotlight high-payoff digital skills proficiency targets for exploiting FBCB2 capabilities. The Leader's Primer identifies critical FBCB2 capabilities, key enablers for tactical success, and common exploitation pitfalls. The trainer-oriented Exploitation 
Tool inventories high-priority FBCB2 user skills and tasks, and presents detailed observation guidelines for obtaining critical performance data. Both products are geared for the platoon, company and battalion echelons. The complete Leader's Primer and Exploitation Tool appear separately in a Research Product.

\section{Utilization of findings:}

The findings of this project establish a basic architecture for measuring high-payoff proficiency targets for FBCB2 operators and users. As a cornerstone, the knowledge base can be used to enhance commanders' assessment tools, digital training products and tools, proficiency measurement methods, and performance feedback capabilities. The ultimate benefits can optimize digital training programs through enhanced assessment.

A variety of personnel involved in FBCB2-enabled unit training can use the Leader's Primer and the Exploitation Tool as planning tools and job aids. By employing these products unit leaders and trainers can enhance the payoff realized from their training exercises, ultimately saving training resources and boosting combat effectiveness on the battlefields of the $21^{\text {st }}$ Century. 


\section{EXPLOITING FBCB2 CAPABILITIES THROUGH REALISTIC FEEDBACK}

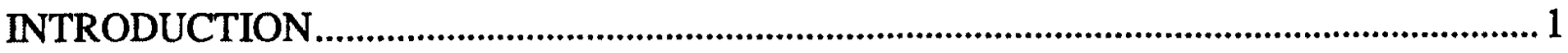

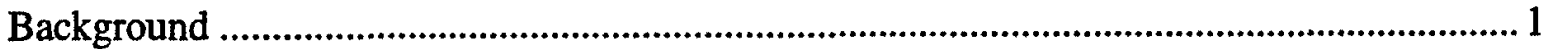

Problem Definition ...................................................................................................................

Technical Objectives ................................................................................................................

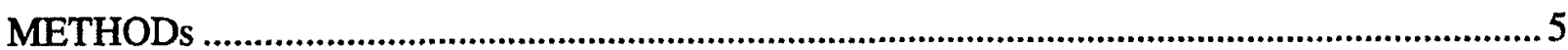

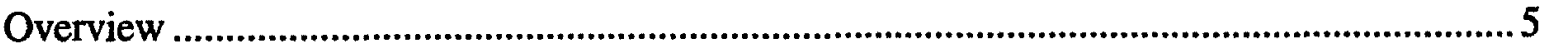

Review of Systems Capabilities ................................................................................................

Data Collection and Reduction .........................................................................................6

Analytical Procedures .............................................................................................................. 8

Development of Products ................................................................................................

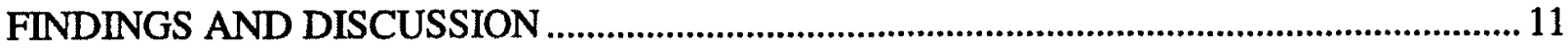

Digital Performance Dimensions ............................................................................................... 11

Factors Influencing Digital Performance .............................................................................. 19

Indicators of Digital Proficiency ............................................................................................. 23

CONCLUSIONS AND RECOMMENDATIONS.........................................................................2

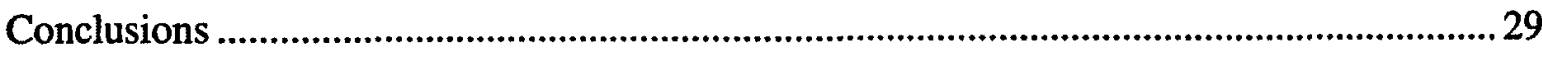

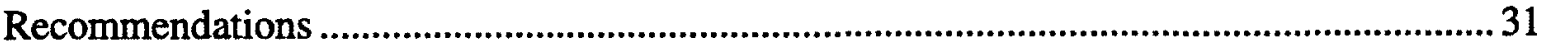

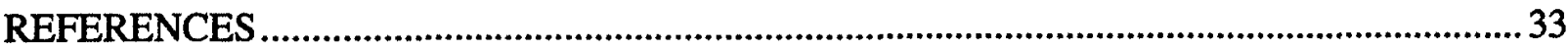

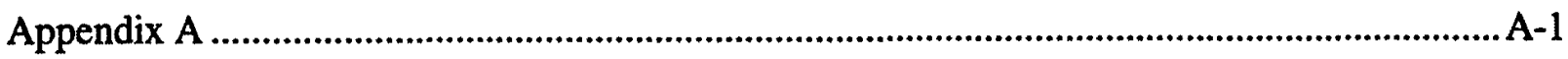

Interview Questions for Each Echelon ................................................................................... A-1

Appendix B ...................................................................................................................... B-1

List of Acronyms and Abbreviations ………….................................................................... B-1 


\section{LIST OF TABLES}

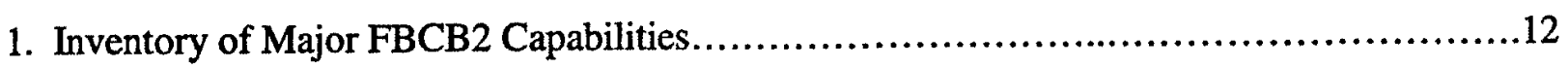

2. Inventory of Keys to Success for Each Major FBCB2 Capability............................13

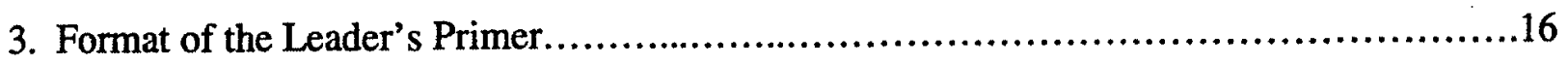

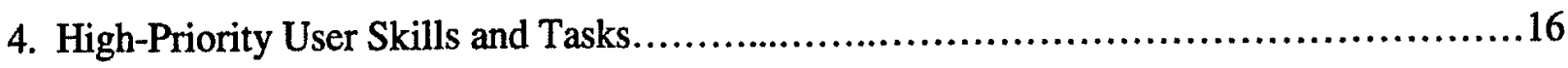

5. High-Priority Network Management Skills (Lower TD)....................................19

6. Matrix Format of FBCB2 Exploitation Tool, with Sample Entries.............................26

7. AAR Questions for Shifting the Spotlight to FBCB2 Exploitation.........................27 


\section{EXPLOITING FBCB2 CAPABILITIES THROUGH REALISTIC FEEDBACK}

\section{INTRODUCTION}

In support of the future force, the U.S. Army Research Institute (ARI) has been investigating the special training needs generated by digitization. In the project entitled $F B C B 2$ Training Feedback Variables (FBCB2-TFV), ARI's Simulator Systems Research Unit (SSRU) explored the performance feedback dimensions of the Force XXI Battle Command Brigade and Below (FBCB2), a primary digital command and control tool. The project keyed on the Army's challenges in capturing digital proficiency data during the evolution of system software. As the software versions continue to advance the tool's capabilities, units are developing tactics, techniques, and procedures (TTPs) that apply to digital command and control, rather than a specific software version. Army training developers have yet to fully incorporate detailed digital criteria in mission training plans (MTPs). In the absence of published evaluation criteria, trainers and unit evaluators feel pressure in determining digital skill proficiency that transcends software versions and upgrades. This research establishes a starting point for measuring digital unit proficiency that will help focus leaders and trainers on high-payoff targets.

This work is part of the "Methods and Measures of Commander-Centric Training" Science and Technology Objective (STO). The goals of this STO are to develop and assess command, control, communication, computers, intelligence, surveillance, and reconnaissance (C4ISR) training methods for Future Combat Systems (FCS) Units of Action, by 2005. This STO supports:

- the U.S. Army Training and Doctrine Command (TRADOC),

- the Program Executive Office for Simulation, Training, and Instrumentation (PEO STRI)

- the Project Manager for Future Combat Systems (PM FCS)

This report presents the methods and findings of the FBCB2-TFV project. It is intended as a guide for unit trainers and observers striving to optimize the digital training experience. The report also provides valuable information for training developers working to create or improve realistic digital training programs. A great deal of practical information was organized for the $4^{\text {th }}$ Infantry Division (4ID) and $1^{\text {st }}$ Cavalry Division (1CD) in two guides, an FBCB2 Exploitation Tool and a Leader's Primer for Exploiting FBCB2. A companion report (Leibrecht, Lockaby, \& Meliza, in preparation) presents the complete guides. Both divisions have received these guides to assist them during operations, including deployment.

\section{Background}

The battlefields of the $21^{\text {st }}$ century will rely increasingly on information technologies to acquire, exchange, and employ timely information throughout the battlespace (e.g., U.S. Department of the Army, 2001). The U.S. Army is in the midst of fielding the Army Battle Command System (ABCS), a family of digital command, control, communications, computers, 
and intelligence (C4I) technologies offering substantially improved warfighting capabilities at all echelons. The ABCS family includes the FBCB2 as the workhorse tool for brigade and below elements and the components of the Army Tactical Command and Control System (ATCCS) for the tactical operations centers (TOCs). Effective combat performance will depend heavily on realistic training to enable warfighters to fully realize the benefits of new digital systems. Such training requires valid tools for measuring the proficiency of digital tasks and skills.

Digitizing the Army is an evolutionary process driven by doctrine as well as technology. As the Army's knowledge about harnessing dynamic digital systems increases, TTPs evolve. Knowing how well units can perform requires measures of digital proficiency that are not affected by software upgrades. Through robust digital capabilities, the ABCS tools enable leaders to (a) make better-informed decisions, (b) collaboratively wargame and refine planned courses of action, and (c) rapidly change plans in response to new information. Proper employment of $\mathrm{C} 4 \mathrm{I}$ systems is expected to produce faster decision cycles, better targeting, and greater control over the tactical situation. Success of the digitization efforts hinges on the full exploitation of complex "systems of systems." This in turn requires an understanding of the digital tasks and performance feedback capabilities needed to gain and exploit the advantages these systems offer on the battlefield. Further, it demands an understanding of how to monitor the health of the tactical internet (TI), the connectivity backbone for the ABCS. Without that capability, leaders cannot be assured of the accuracy and completeness of the common operational picture (COP) provided by the $\mathrm{ABCS}$.

In the training arena, digitization has the potential to overwhelm trainers and evaluators with observation requirements (Brown, Anderson, Begley, \& Meliza, 1999; Brown, Nordyke, Gerlock, Begley, \& Meliza, 1998). In addition to observing the same events applicable to analog units, trainers for digitized units must monitor the stream of digital messages, interactions between system operators and digital information users, and even interactions among system operators. One approach for avoiding observation overload is to identify the aspects of digital proficiency that most warrant the attention of trainers, because of their potential contributions to unit effectiveness. Another approach is to tailor observation requirements according to unit digital proficiency levels.

Investigators in ARI have identified candidates for measuring digital skills proficiency, based on performance problems noted at the Army's Combat Training Centers (Barnett, Meliza, \& McCluskey, 2001; Meliza, 2003). Related research with the $4 \mathrm{ID}$ has shown that there is a difference in the digital maturity requirements of brigade staffs versus those of battalion staffs (Dudley, Hill, Johnston, Jones, LeGare, Leibrecht, Longoria, \& Meliza., 2002). The same authors established that some digital performance conditions may call for graduated instead of all-or-none measures of digital skills. There is also evidence that warfighting and training behaviors change as leaders and soldiers gain experience using digital systems (Dudley, Johnston, Jones, Strauss, \& Meliza, 2001). These findings highlight the need for measurement criteria in order to provide adequate feedback to warfighters determined to develop digital skills proficiency. Measurement criteria and guidelines must focus on high-payoff targets to reduce the workload of trainers and observers. Additional research was necessary to determine the high priority measurement targets. 


\section{Problem Definition}

The numerous "advertised" benefits of digitization will not materialize merely because new systems are fielded. Units must develop effective digital skills to reap the benefits promised by the new systems. But how? Combat performance in the future operational environment will depend greatly on realistic training that enables warfighters to fully exploit the advantages of new digital systems. Among other things, standards for training and evaluating those skills must be developed. Trainers need criteria and procedures by which to measure digital proficiency. In the absence of digital TTPs, units have relied on practical experience and on-the-job training of their digital skills. As experience grows, greater maturity increases the likelihood of employing major system capabilities. Some of these digital capabilities serve as notable combat multipliers. The digital combat multipliers are high-payoff skills, those that bridge the gap from situational awareness to situational understanding (Dudley et al., 2001). Some of these skills may align with a particular echelon or mission, while others may apply to all. Measurable targets must be defined for the high-payoff skills in order to assess digital competence. These proficiency targets should not be software version specific, but should apply across time and should help reduce trainer workloads.

Leaders need timely feedback on how well their units execute the high-payoff digital skills. They need to know how well individuals and teams are operating their digital systems and using the available capabilities and information. They also need feedback on connectivity among digital systems. As a critical enabler, connectivity must be maintained and monitored in order for leaders to observe the combat effectiveness of their digital units. Feedback on the health of the TI and the connectivity between TOCs must assure leaders that the picture they view is timely and complete. This facilitates digital command and control, expediting combat decisions. Research is needed to establish indicators of network health and system usage that reveal a unit's level of digital proficiency.

At Fort Hood, Texas, III Corps leaders have established digital training facilities in the Battle Command Training Center (BCTC) to support the training programs of resident digital divisions. Similarly, I Corps leaders have established the Mission Support Training Facility (MSTF) at Fort Lewis, Washington, to help train the Army's first two Stryker Brigade Combat Teams (SBCTs). In both the BCTC and MSTF, trainers and observers routinely face the challenges of measuring digital proficiency levels, and their ranks are growing across the Army. Trainers for collective training exercises in field and simulation environments lack measures and standards for assessing how well units employ digital systems. These standards and the guidance for their application must be carefully structured to avoid overwhelming trainers with observation requirements. An essential goal of this project was to reduce digital performance observation workloads to manageable levels by focusing observers' attention on high-payoff measurement targets and by harnessing automation where feasible. An expanded database was needed to define targets for digital proficiency measurement that will contribute most effectively to achieving digital training objectives. 


\section{Technical Objectives}

The purpose of this research was to establish high-payoff digital proficiency measurement guidance (emphasis on FBCB2), in the context of an architecture for digital proficiency feedback. The ultimate goal was to enhance the efficiency and effectiveness of the observation process for digital training. The following technical objectives drove the planning and execution of the project:

- Identify and describe major capabilities of FBCB2 to influence tactical operations as a function of (a) echelon, (b) mission aspects and (c) frequency of employment.

- Identify high-priority FBCB2 user skills and tasks, and determine which are difficult to perform or acquire.

- Identify the most frequently occurring problems in operating FBCB2 systems.

- Develop detailed guidelines for measuring levels of performance proficiency for high-payoff FBCB2 user digital tasks. 


\section{METHODS}

\section{Overview}

The overall project strategy leveraged the experience accumulated in the Army's digitization of Fort Hood units. This experience resided with then-current leaders of digital units, former leaders of digital units, contractors supporting digitized units with system-specific and general guidance, and BCTC classroom instructors. The U.S. Army Training and Doctrine Command (TRADOC) Warrior-T office at Fort Hood has developed numerous products that included describing digital tasks (Warrior-T 2001a, 2001b, 2002a, 2002b, 2002c). In some cases these products describe FBCB2 tasks, while in other cases they describe the systems used by the battle staff that must interoperate with FBCB2. Warrior-T personnel were a valuable source of information regarding relationships between FBCB2 tasks and unit tactical proficiency. Contractors that directly support unit operation of digital systems were a valuable source of information regarding the problems reported and questions asked by operators of digital systems.

The intent of this effort was to develop an FBCB2 measurement architecture to set the stage for later empirical investigations. Major steps associated with developing the architecture were as follows:

- Identify digital activities that warrant measurement

- Describe the tactical significance of the activities to be measured

- Identify the echelon(s) to be observed

- Describe the tactical events that set the stage for each observation

- Identify the data and data sources used to assess performance

- Describe information that might be provided by automated systems to support measurement

- Identify major variables influencing the use of $\mathrm{FBCB} 2$ capabilities

Analysts developed digital measurement guidelines in several steps. The team first identified more than 20 high-payoff FBCB2 user tasks. Then they consolidated these individual tasks into categories based largely on 4ID warfighter estimates of their importance for combat success. The team resolved to develop critical tasks that did not depend on specific software versions. For the final set of digital skills, the analysts proceeded to define performance goals, crafted instructions for observing and measuring performance, then elaborated the measurement context. Coordination with warfighters helped validate and refine the guidelines. In addition, by request the team supported a battalion level digital training exercise by, in part, testing an early version of the measurement guidelines.

The outcomes of this work included (a) the identification of fifty FBCB2 digital performance goals arranged under nine topical areas that warrant measurement, (b) a description of the tactical significance of each goal, and (c) guidance for measuring unit performance with respect to each goal. One version of this information was packaged as a pocket-sized, laminated booklet and distributed to each unit and vehicle commander in the $1^{\text {st }}$ and $2^{\text {nd }}$ Brigades of the 4ID to support their deployment to Southwest Asia. The product also serves to indicate the information displays that automated After Action Review (AAR) systems need to produce to provide units with feedback regarding their employment of FBCB2. These displays would 
employ breakouts of the digital message traffic and breakouts of electronically collected data on operator interactions with FBCB2. Another outcome of this work was the identification of FBCB2 capabilities that are not being consistently employed by units at battalion and/or company/platoon level, what is lost by not using the capability, and measures leaders can use in deciding whether the capabilities are being employed in a particular unit. Findings also included a description of the major variables influencing the use of FBCB2 capabilities. Each of these variables impacts the use of more than one FBCB2 capability. Knowing where a unit stands in reference to these variables enables a trainer to reduce the number of digital performance goals to be measured. For example, if a unit lacks standing operating procedures (SOPs) for employing digital systems, the stage will not have been set for addressing certain performance goals.

\section{Review of Systems Capabilities}

The team reviewed relevant documentation of the FBCB2 system (e.g., system user manuals, system requirements documents, digital operating guides) to inventory the functional capabilities including feedback features. Documentation of ATCCS systems and the TI was also reviewed for description of feedback capabilities. Where appropriate, the team inspected actual ABCS systems to verify or supplement the written information.

Much of the information about high-payoff FBCB2 capabilities was derived from two previous reports in this series. Dudley et al. (2001) interviewed experienced digital leaders to identity and describe changes in behaviors and attitudes of units as they gained experience using digital systems. For example, a number of unit leaders noted that they no longer had to constantly labor with voice radio to keep track of the location of their subordinates, because they were able to track these locations by looking at their FBCB2 situational awareness displays. Dudley et al. (2002) employed a variety of digital subject matter experts (SMEs) to describe, in substantial detail, how a unit might use digital systems to reduce fratricide and/or gain greater control over when and how contact is made with the enemy. For example, commanders can use FBCB2 line-of-sight tools and FBCB2 displays showing the location of enemy forces to predict when and where their unit is likely to make visual contact with the enemy. These sources of information helped identify critical FBCB2 capabilities to be addressed by meas urement efforts, and they also provided examples of higher levels of proficiency.

\section{Data Collection and Reduction}

\section{Interviews}

Interview participants. The research team's lead SME interviewed a sample of $1^{\text {st }}$ Brigade Combat Team (BCT), 4ID leadership in the unit's own facilities (Fort Hood) and at their convenience. The senior leadership sample consisted of the brigade commander, brigade executive officer and staff, an armor and infantry battalion commander, armor battalion staff, and multiple company commanders and platoon leaders. The team also interviewed soldiers and leaders as they completed Key Leader's Training at the BCTC. These participants included a company executive officer, an engineer platoon leader, multiple scout leaders, a battalion maintenance team chief, and a supply sergeant. In addition, informal interviews were held with 
two recently retired digital operations SMEs, all with command experience plus service with the 4ID, and a few retired senior non-commissioned officers (NCOs) having contemporary active duty experience in the 4ID.

Interview procedures. Most of the interviews were conducted in the context of Fort Hood's umbrella week. The interview process probed for knowledge of digital capabilities and their supporting digital skills, in a project-wide context addressing all technical objectives. Interviews were designed to capture experience and insights of leaders and soldiers. The intent was to delve into a reflective thought process concerning the view of their digital skills, gather data based on actual experience, and clarify information obtained from other sources.

The interview team consisted of at least one SME serving as the facilitator and note-taker for all sessions. In order to structure the interviews, the facilitator used an interview guide containing general instructions and questions of interest (Appendix A). Each session lasted approximately two hours, whether one-on-one or group interview. For some of the group interviews, questionnaires were used to facilitate concurrent capture of data. A record of each 4ID interview session was prepared from notes made during the session.

Interview questions. Appendix A contains the interview guide used for the majority of the sessions. The queries targeted the unit's digital operation practices, changes in skills and proficiency with experience, and operational problems. Specific questions addressed:

- Unit activities for keeping FBCB2 systems and the network operational

- Rules and procedures for managing connectivity, filters, files, etc.

- Use of FBCB2 tools or features to accomplish specific tasks (e.g., planning fires)

- Means for establishing and maintaining the COP

- Use of planning products such as maneuver plans and orders

- Communicating and sharing information

- Progression to higher levels of proficiency, including skills and insights

- Occurrence (timing, frequency, mastery) of FBCB2 operating and usage problems

- FBCB2 capabilities that discourage routine use because they are difficult to employ

- Monitoring the currency, completeness and evolution of digital products

- Detection and resolution of gaps in digital information

\section{Observations}

The research team observed battalion exercises conducted in live, virtual, and constructive simulation environments, and small unit exercises conducted in the Close Combat Tactical Trainer (CCTT). The project team provided personnel to serve observer/controller (OC) functions to support much of this training. This provided opportunities to test early versions of digital measurement guidance and to question OCs regarding digital proficiency measurement insights. Occasionally, informal interviews with unit leaders were held in conjunction with the exercises, notably in association with AARs. 


\section{Analytical Procedures}

The cumulative data contained qualitative information originating from system-related documents, interview records, and summaries of observation sessions. Separate but parallel procedures were used for analyzing and integrating the data related to (a) the key variables of echelon, mission type, and task difficulty and (b) FBCB2 operating problems. Given the qualitative nature of the data, strictly non-quantitative techniques were used for analysis. The knowledge and judgment resident within the research team were leveraged, especially where gaps in interview results or available documentation occurred.

\section{Influence of Key Variables}

The research plan called for examining how echelon (platoon through battalion), mission type, and task difficulty influence the way FBCB2 capabilities impact tactical operations. Task difficulty was estimated from interview comments and from analysis of FBCB2 operating/usage problems (see below). Factors of interest also included the frequency of employing FBCB2 capabilities as well as the level of digital experience among operators and leaders.

The lead SME reviewed the accumulated data in consecutive passes, deriving implications for each variable in the process. In reality some of the variables had to be considered in combination, especially echelon and frequency of usage. In tabulating the frequency of usage for the various capabilities, the SME also took into account the information needs for a given position. The lead SME then provided the resulting implications and conclusions to participating SMEs for their analysis and elaboration. The resulting inputs were compiled by the lead SME, then team members reviewed the preliminary findings and resolved substantive issues.

It is important to note that the team's determinations are preliminary and warrant additional study.

\section{Problems Associated with FBCB2 Operation}

Problems emerge when the user cannot accomplish an FBCB2 function due to lack of digital training/experience or when he concludes the payoff of a function is not worth the effort required. The analysis of FBCB2 operating problems relied on soldiers' interview/questionnaire comments as well as the expertise of the team's SMEs. In addition, the team interviewed FBCB2 field service representatives (FSRs) at Fort Hood and reviewed FSR reports. Task difficulty figured prominently in the analysis, as did attempts to investigate the role of digital experience. The analysts concentrated on identifying problems in using FBCB2 and changes in problems across time. The team also explored whether and when experience influences the operator/user's ability to circumvent and overcome problems. 


\section{Development of Products}

\section{Capabilities Matrix}

After preparing a draft list of FBCB2 capabilities, the team queried 4ID warfighters in interview sessions regarding the importance of each capability in terms of its contribution to tactical operations. Team members compiled and organized the results in light of their own digital knowledge and tactical application. The collective results regarding FBCB2 capabilities and their applicability/utility were collated into a matrix of digital capabilities, containing the following elements for each capability: tactical importance, implementing actions, and frequency of employment. In those cases where the capability was not fully employed, the team examined the root cause, such as lack of awareness/training or perceived lack of payoff. The team coordinated with 4ID leaders and operators to obtain informal validation of the matrix, which was refined by incorporating their input.

In support of Fort Hood units on alert to deploy to Southwest Asia, the team expanded the FBCB2 capabilities data and organized the cumulative information into a consolidated matrix. To the elements of information described in the preceding paragraph the team added performance problems and sources of data pointing to the problems. The resulting Leader's Primer was converted to a format convenient for carrying to the field.

Each unit leader in the 4ID's $1^{\text {st }}$ and $2^{\text {nd }}$ Brigades was provided with a laminated, pocketsized version of the Leader's Primer for Exploiting FBCB2. At the request of the III Corps Digital Training Chief, all unit leaders in the $1 C D$ were also provided with field expedient copies of the primer.

\section{Exploitation Tool}

An important objective was to develop guidelines for digital trainers by integrating the results regarding high-payoff digital skills, FBCB2 operating problems, and the influence of echelon and mission type. The team aimed to produce an observer-friendly tool that could focus measurement activities and facilitate high-payoff performance feedback. There were three practical goals of the Exploitation Tool: (a) reduce the overall workload of exercise observers, (b) optimize the training value realized by digital units, and (c) provide a guide for leaders to assess the digital proficiency of their unit.

Relying heavily on interview input, the team judged the complete set of FBCB2 capabilities to determine those offering the best return for investment of training effort. The process involved ranking the list of major capabilities against their expected contributions to combat effectiveness. This produced a set of nine major capabilities providing the highest payoff and thus warranting the attention of trainers. Building on the earlier matrix of FBCB2 capabilities, the team then developed observation guidelines for trainers and leaders regarding each of the nine selected capabilities. The guidelines inventoried specific digital actions (performance goals), echelon applicability, prompting conditions (triggers), and relevant sources of performance data. The team compiled the results in a matrix format designed for easy use by 
leaders, observers and trainers. The final Exploitation Tool spelled out instructions for when, where, how, and why to collect critical performance information.

Each unit leader and vehicle commander in the 4ID's $1^{\text {st }}$ and $2^{\text {nd }}$ Brigades was provided with a laminated, pocket-sized version of the $F B C B 2$ Exploitation Tool. At the request of the III Corps Digital Training Chief, all unit leaders and vehicle commanders in the $1 \mathrm{CD}$ were also provided with field expedient copies of the tool. 


\section{FINDINGS AND DISCUSSION}

This chapter presents and discusses the project's findings resulting from the warfighter interviews, document and system reviews, and analytical efforts. The following sections organize the presentation:

- Digital Performance Dimensions

- Factors Influencing Digital Performance

- Indicators of Digital Proficiency

The findings focus on recurring patterns and critical insights conveying the weight of qualitative evidence and concentrate on the fundamental performance dimensions that characterize digital operations at battalion echelon and below, excluding battle staff operations. The results provide an initial architecture for measuring digital proficiency of units employing FBCB2 capabilities.

\section{Digital Performance Dimensions}

\section{FBCB2 Capabilities}

As the primary digital tool for small units, FBCB2 brings to battle command elements and maneuver platforms a host of functional capabilities centering around command, control, and communications. The team's analysis plus input from the 4ID warfighters revealed more than 20 major capabilities (Table 1) falling in five operational areas:

- Basic features for establishing and maintaining an effective operating environment

- Essential capabilities for supporting robust visualization of the battlefield

- Tools to support planning and preparing for combat missions

- Key functions for exchanging and managing tactical information

- High-priority capabilities to support force mobility and maneuver

The FBCB2 capabilities that emerged from this project (Table 1) represent both operator and user domains. Some of the functional features (e.g., setting filters, clearing queues and logs) are performed by system operators. These capabilities convey specific actions that correspond closely with "buttonology." On the other hand, the majority of the functional features are orchestrated by users (battle captains or company commanders, for example) and encompass a family of specific actions. Examples of user-based capabilities include planning and controlling indirect fires and supporting maneuver decisions. There is no practical dichotomy between user and operator capabilities. Rather, they lie along a spectrum of functional features stretching from highly specific actions to broad, multi-action capabilities, from simple (yet critical) to complex (and equally critical) features.

Relative frequency of employment is one factor to consider in selecting high-payoff digital proficiency targets. The middle two columns of Table 1 give estimates of how often the various capabilities are actually used in the 4ID. The team's SMEs reached a consensus on the ratings, in light of their own knowledge plus warfighters' interview comments. In general, basic planning and command and control capabilities are employed more frequently, while housekeeping and analytical functions are less frequent. Usage differences between battalion 
echelon and lower echelons are potentially important. These differences are addressed below in the discussion of the influence of Echelon and Mission Phase. The probability-of-exploitation ratings do not directly indicate the relative importance of any capability, but they may well correlate with user perceptions of value or benefits gained. Table 1 provides illustrative evidence supporting the low to medium ratings in the Probability of Exploitation columns.

Table 1

Inventory of Major FBCB2 Functional Capabilities

\begin{tabular}{|c|c|c|c|}
\hline \multirow[b]{2}{*}{ FBCB2 Capabilities } & \multicolumn{2}{|c|}{$\begin{array}{l}\text { Probability of } \\
\text { Exploitation }\end{array}$} & \multirow{2}{*}{$\begin{array}{c}\text { Evidence of } \\
\text { Exploitation Problems }\end{array}$} \\
\hline & Bn & Co/Plt & \\
\hline \multicolumn{4}{|c|}{ Digital Basics } \\
\hline Establish proper communication network & High & High & \multirow{5}{*}{$\begin{array}{l}\text { FSRs are called to "fix" operator level } \\
\text { problems such as unconnected cables, } \\
\text { systems not tumed on, alerts filtered } \\
\text { out. File naming conventions are not in } \\
\text { SOPs. }\end{array}$} \\
\hline Clear queues and logs & Med & Low & \\
\hline Set fitters and respond to alerts & Low & Low & \\
\hline Use filing/naming conventions & Low & Low & \\
\hline Perform maintenance and troubleshooting & Low & Low & \\
\hline \multicolumn{4}{|c|}{ Battlefield Visualization } \\
\hline Relate threat to own/unit location & High & Med/Low & \multirow{4}{*}{$\begin{array}{l}\text { Field observations and interviews reveal } \\
\text { Co/Plt leaders lack proficiency to relate } \\
\text { threat to own location. SOPs don't } \\
\text { address tailoring SA picture, managing } \\
\text { Red icons, or posting obstacle overlays. }\end{array}$} \\
\hline Tailor SA picture & Low & Low & \\
\hline Manage Red icons & Med & Low & \\
\hline Post obstacle overlays & High & Low & \\
\hline \multicolumn{4}{|c|}{ Mission Planning and Preparation } \\
\hline Apply Line of Sight (LOS) tool for terrain analysis & Low & Low & \multirow{6}{*}{$\begin{array}{l}\text { Interviews show users forget to use } \\
\text { LOS tool. SIMEX observation reveals } \\
\text { absence of preset CFFs and logistics } \\
\text { players. SOP doesn't address overlay } \\
\text { naming and filing. Interviews show } \\
\text { insufficient digital expertise to support } \\
\text { wargaming and digital rehearsals. }\end{array}$} \\
\hline Apply LOS tool for perimeter defense planning & Low & Low & \\
\hline Use FBCB2 to plan and control fire support & High & Med & \\
\hline Use FBCB2 for logistical planning/preparation & Low & Low & \\
\hline Construct and update overlays & High & Low & \\
\hline Leverage FBCB2 in multi-echelon wargaming & Med & Low & \\
\hline \multicolumn{4}{|c|}{ Tactical Information Exchange } \\
\hline Prepare and manage messages and graphics & High & Med & \multirow{3}{*}{$\begin{array}{l}\text { Review of unit SOPs reveals lack of } \\
\text { guidance on file naming/storage and } \\
\text { message receipt confirmation. }\end{array}$} \\
\hline Disseminate messages and graphics & High & Med & \\
\hline Confirm reception of critical messages & Med & Low & \\
\hline \multicolumn{4}{|c|}{ Force Mobility and Maneuver } \\
\hline Use FBCB2 to plan and execute movements & High & Med & \multirow{3}{*}{$\begin{array}{l}\text { SOPs lack guidance on organizing } \\
\text { folders, saving/posting overlays, and } \\
\text { disseminating route maps. }\end{array}$} \\
\hline Leverage FBCB2 in maneuver decisions & High & Med & \\
\hline Exploit FBCB2 in tratricide prevention & High & Med & \\
\hline
\end{tabular}

The capabilities listed in Table 1 represent those FBCB2 features that play a major role in successful tactical operations of the 4ID. Considering operational variations across time and units, the list may offer only limited generality. At the same time, the inventory provides a reasonable snapshot of the more valuable FBCB2 capabilities supporting Force XXI operational requirements. It represents an important step in focusing digital proficiency measurement methods so as to reduce trainer/observer workload and enhance training effectiveness. In the FBCB2-TFV project, the inventory provided the springboard for identifying high-payoff user digital skills. 
The next step involved identifying the exploitation steps associated with tactical success. For each major FBCB2 capability the team's SMEs discerned as many as ten operational keys to success (Table 2). These represented indicators signaling that critical enablers are in place for successfully exploiting the power of the FBCB2. The team also compiled common performance problems that hinder FBCB2 exploitation, also seen in Table 2.

Table 2

Inventory of Keys to Success for Each Major FBCB2 Capability

\begin{tabular}{|c|c|c|}
\hline $\begin{array}{l}\text { Major Capabilities - } \\
\text { Tactical Importance }\end{array}$ & Keys to Success & Exploitation Pitfalls \\
\hline \multicolumn{3}{|c|}{ Digital Basics } \\
\hline $\begin{array}{l}\text { Establish proper } \\
\text { communication } \\
\text { network - so Blue } \\
\text { picture is accurate. }\end{array}$ & $\begin{array}{l}\text { - SINCGARS/EPLAS have correct COMSEC } \\
\text { - EPLRS and CSMA servers are operational } \\
\text { - All INCs are operational } \\
\text { - Digital commo checks are part of PCCs/PCls } \\
\text { - All FBCB2 platforms are reporting on TI } \\
\text { - BLUFOR icons are visible on FBCB2 display }\end{array}$ & $\begin{array}{l}\text { Leaders and operators at all } \\
\text { echelons fail to establish a fully } \\
\text { functional network; often } \\
\text { without realizing it. }\end{array}$ \\
\hline $\begin{array}{l}\text { Clear queues and logs } \\
\text { - to avoid frustration } \\
\text { of sluggish systems }\end{array}$ & $\begin{array}{l}\text { - Queves and logs are cleared prior to LD } \\
\text { - Refresh rate is optimal at start of mission } \\
\text { - Queues \& logs are cleared after each mission } \\
\text { - User detects slow down and takes action } \\
\text { - Users know when it's time to clear queueshogs }\end{array}$ & $\begin{array}{l}\text { Co and Plt do not initiate } \\
\text { clearing, due to fear of losing } \\
\text { info or lack of time. Operators } \\
\text { call } 31 U \text { when system slows } \\
\text { down. }\end{array}$ \\
\hline $\begin{array}{l}\text { Set filters and respond } \\
\text { to alerts - enabling } \\
\text { better SU and faster } \\
\text { decisions }\end{array}$ & $\begin{array}{l}\text { - TACSOP specifies filter setting procedures } \\
\text { - Filters are set in advance, according to mission } \\
\text { - Filter settings produce clear, standard COP } \\
\text { - Filter settings enable hazard alerts } \\
\text { - Users respond to alerts with appropriate action } \\
\text { - Users adjust filter settings as necessary }\end{array}$ & $\begin{array}{l}\text { Users at all echelons fail to } \\
\text { achieve standard COP, often } \\
\text { without realizing the signifi- } \\
\text { cance of the COP. Alerts are } \\
\text { filtered out or ignored. } \\
\text { Vehicles enter minefields. }\end{array}$ \\
\hline $\begin{array}{l}\text { Use file naming } \\
\text { conventions - to } \\
\text { retrieve critical info } \\
\text { faster }\end{array}$ & $\begin{array}{l}\text { - TACSOP specifies file naming conventions } \\
\text { - Order \& overlay names are assigned per SOP } \\
\text { - Folders are created IAW mission } \\
\text { - Folders are identified with DTG } \\
\text { - Files are saved in correct folder } \\
\text { - Users retrieve and post correct files readily }\end{array}$ & $\begin{array}{l}\text { Users are unsure how to set } \\
\text { up folders and name files, due } \\
\text { to lack of SOPs or training. } \\
\text { They find it difficult to find } \\
\text { correct files, and may display } \\
\text { incorrect overlays. }\end{array}$ \\
\hline $\begin{array}{l}\text { Perform maintenance } \\
\text { and trouble-shooting - } \\
\text { to sustain continuous } \\
\text { communications }\end{array}$ & $\begin{array}{l}\text { - Operators or users detect problems promptly } \\
\text { - Diagnostic tools (Help, SysAdmin) are used } \\
\text { - Prompt action avoids lengthy downtime } \\
\text { - Users call } 31 \text { Us only when all else fails } \\
\text { - Workarounds are used infrequently } \\
\end{array}$ & $\begin{array}{l}\text { Operators fail to use trouble- } \\
\text { shooting techniques, due to } \\
\text { lack of training or time. Users } \\
\text { call support personnel } \\
\text { unnecessarily. }\end{array}$ \\
\hline \multicolumn{3}{|c|}{ Battlefield Visualization } \\
\hline $\begin{array}{l}\text { Relate threat to } \\
\text { own/unit location - to } \\
\text { protect Blue forces and } \\
\text { dominate enemy }\end{array}$ & $\begin{array}{l}\text { - CCIRs are disseminated to lowest echelons } \\
\text { - Users report CCIRs as they are encountered } \\
\text { - Users relate own/unit icons to Red locations } \\
\text { - Planned moves are related to Red assets } \\
\text { - All plattorms display obstacle overtays } \\
\text { - Blue forces avoid danger zones }\end{array}$ & $\begin{array}{l}\text { Below TF TOC, leaders fail to } \\
\text { monitor CCIRs. Co/PIt view } \\
\text { Red picture but fail to analyze } \\
\text { risk to their operations. Blue } \\
\text { vehicles enter danger zones. }\end{array}$ \\
\hline $\begin{array}{l}\text { Tailor SA picture - to } \\
\text { enhance decisions thru } \\
\text { better SU }\end{array}$ & $\begin{array}{l}\text { - BOS-based filtering clarifies SA picture } \\
\text { - Collapse/expand function reduces clutter } \\
\text { - BFA drives filters for Red picture } \\
\text { - CM function suits logistics elements in offense } \\
\text { - Slower Blue update rate suits defense } \\
\text { - CM function suits other TFs in reconstitution }\end{array}$ & $\begin{array}{l}\text { Leaders and operators at all } \\
\text { echelons fail to tailor SA } \\
\text { picture for current operations. } \\
\text { Screens become cluttered and } \\
\text { hard to follow. }\end{array}$ \\
\hline
\end{tabular}




\begin{tabular}{|c|c|c|}
\hline $\begin{array}{l}\text { Major Capabilities - } \\
\text { Tactical Importance }\end{array}$ & Keys to Se ess & Exploltation Pitfalls \\
\hline $\begin{array}{l}\text { Manage Red icons-to } \\
\text { enhance threat picture }\end{array}$ & $\begin{array}{l}\text { - TACSOP specifies SPOT } \\
\text { - Red picture gives insight } c \text { anemy forces } \\
\text { - Responsibility for updating rined icons is clear } \\
\text { - SPOT reports are updated as needed } \\
\text { - Users question when Red icons become stale } \\
\text { - Observer hands off responsibility when necessary }\end{array}$ & $\begin{array}{l}\text { Co and PIt fail to update Red } \\
\text { icons and hand off ownership } \\
\text { when originator loses visual } \\
\text { contact. Red icons fade as } \\
\text { they become stale. }\end{array}$ \\
\hline $\begin{array}{l}\text { Post obstacle overlays } \\
\text { - to avold Blue } \\
\text { attrition }\end{array}$ & $\begin{array}{l}\text { - Obstacle overlays are disseminated promptly } \\
\text { - Users post obstacle overlays promptly } \\
\text { - Users name and save overlays properly } \\
\text { - Minefield alerts trigger avoidance actions } \\
\text { - Engineers are notified of new minefields } \\
\text { - Obstacle overlays are updated as necessary }\end{array}$ & $\begin{array}{l}\text { Co/Plt lose wamings by failing } \\
\text { to post obstacle overlay, or } \\
\text { posting old overlay, or failing to } \\
\text { find misfiled overlay. Blue } \\
\text { vehicles enter danger zones. }\end{array}$ \\
\hline \multicolumn{3}{|c|}{ Mission Planning and Preparation } \\
\hline $\begin{array}{l}\text { Apply LOS tool for } \\
\text { terrain analysis - to } \\
\text { enhance Blue Force } \\
\text { protection }\end{array}$ & $\begin{array}{l}\text { - LOS tool replaces analog map technique } \\
\text { - TACSOP specifies digital terrain analysis role } \\
\text { - Inter-visibility estimates are more precise } \\
\text { - Outcomes appear in planning products } \\
\text { - Vulnerable areas of route are identified quickly } \\
\text { - Future engagement areas emerge readily }\end{array}$ & $\begin{array}{l}\text { Leaders and operators fail to } \\
\text { use LOS tool for terrain } \\
\text { analysis, reverting to analog } \\
\text { map recon. Vulnerable areas } \\
\text { are overtooked. Likely enemy } \\
\text { contact is misjudged. }\end{array}$ \\
\hline $\begin{array}{l}\text { Apply LOS tool for } \\
\text { perimeter defense } \\
\text { planning - to Improve } \\
\text { speed and accuracy }\end{array}$ & $\begin{array}{l}\text { - Digital sector sketches are the norm } \\
\text { - Circular LOS tool is used during planning } \\
\text { - Fields of fire are optimized quickly } \\
\text { - Placement/coverage of LPs/OPs is verified } \\
\text { - Enemy avenues of approach are illuminated } \\
\text { - Threat fields of fire are predicted accurately }\end{array}$ & $\begin{array}{l}\text { Units are not leveraging LOS } \\
\text { tool for perimeter defense } \\
\text { planning. This results in } \\
\text { unknown dead space and } \\
\text { degrades placement of } \\
\text { LPS/OPs. }\end{array}$ \\
\hline $\begin{array}{l}\text { Use FBCB2 to plan and } \\
\text { control fire support - } \\
\text { to enhance precision } \\
\text { and avold fratricide }\end{array}$ & $\begin{array}{l}\text { - Digital tools replace analog map techniques } \\
\text { - NFZ/NFARFL appear on operational overlay } \\
\text { - TACSOP specifies digital CFF procedures } \\
\text { - CFF requests are planned in advance } \\
\text { - Pre-planned CFFs are set in Quick Send queue } \\
\text { - Fire support triggers appear on SA displays } \\
\text { - SA influences decisions to deny fires } \\
\end{array}$ & $\begin{array}{l}\text { Co and PIt leaders typically fail } \\
\text { to pre-plan CFFs, leading to } \\
\text { delays in execution. Non-use } \\
\text { of COP capabilities can allow } \\
\text { fratricide situations to develop. }\end{array}$ \\
\hline $\begin{array}{l}\text { Use FBCB2 to support } \\
\text { logistlcal planning and } \\
\text { preparation - to } \\
\text { bolster resupply } \\
\text { procedures }\end{array}$ & $\begin{array}{l}\text { - Digital CSS overlay accompanies OPORD } \\
\text { - Circular LOS tool is used to plan log sites } \\
\text { - Digital CSS rock drills are pertormed } \\
\text { - Digital LOGSTATs/PERSTATs are the norm } \\
\text { - LOGSTATs are property routed, reach CSSCS } \\
\text { - Supply Point icons are established } \\
\text { - Coordination for supplies occurs digitally } \\
\text { - Transporters use FBCB2 Nav tool for deliveries } \\
\text { - Leaders find support elements via SA picture } \\
\end{array}$ & $\begin{array}{l}\text { CSS annex and overlay are } \\
\text { often omitted or disseminated } \\
\text { late. Units typically bypass } \\
\text { CSS rock drills and struggle } \\
\text { with LOGSTAT rollup. Supply } \\
\text { point capability is rarely used. }\end{array}$ \\
\hline $\begin{array}{l}\text { Construct and update } \\
\text { overlays - to enhance } \\
\text { COP and SU }\end{array}$ & $\begin{array}{l}\text { - Digital overlays are the norm (vs. hardcopy) } \\
\text { - Overlays are named IAW standards (TACSOP) } \\
\text { - Digital overlays are disseminated via MDL } \\
\text { - Complete dissemination occurs on first attempt } \\
\text { - Every plattorm receives obstacle overlay } \\
\text { - Users post overlays prior to LD } \\
\text { - Overlays are updated as required }\end{array}$ & $\begin{array}{l}\text { Dissemination of overlays to } \\
\text { companies and platoons is } \\
\text { often abortive, fractionated or } \\
\text { incomplete. Users who do } \\
\text { receive overlays often fail to } \\
\text { save them properly and post } \\
\text { them to the display. }\end{array}$ \\
\hline $\begin{array}{l}\text { Leverage FBCB2 in } \\
\text { multi-echelon war- } \\
\text { gaming - to optimize } \\
\text { synchronization }\end{array}$ & $\begin{array}{l}\text { - Wargaming routinely involves FBCB2 } \\
\text { - COA analysis is related to SA picture } \\
\text { - Digital rehearsals occur routinely } \\
\text { - Nav tool helps estimate Blue/Red rate of march } \\
\text { - Likely exposure to Red weapons is illuminated } \\
\text { - Vulnerable areas are identified for BLUFOR } \\
\text { - FBCB2 tools influence decision making }\end{array}$ & $\begin{array}{l}\text { Companies and platoons fail to } \\
\text { use FBCB2 for mission } \\
\text { analysis. Only partial } \\
\text { capabilities of Nav tools are } \\
\text { used. Digital rehearsals occur } \\
\text { rarely and without strip maps. }\end{array}$ \\
\hline
\end{tabular}




\begin{tabular}{|c|c|c|}
\hline $\begin{array}{l}\text { Major Capablitities - } \\
\text { Tactical Importance }\end{array}$ & Keys to Success & Exploitation Pitfalls \\
\hline \multicolumn{3}{|c|}{ Tactical Information Exchange } \\
\hline $\begin{array}{l}\text { Prepare and manage } \\
\text { messages/graphics - } \\
\text { to facilitate information } \\
\text { retrieval }\end{array}$ & $\begin{array}{l}\text { - Users set up message folders during PCCs } \\
\text { - Address groups are verified after UTR } \\
\text { - Digital OPORDs/overlays are the nom } \\
\text { - File names follow TACSOP conventions } \\
\text { - Graphics are simple and within size limits } \\
\text { - Graphics are updated as required } \\
\text { - Users purge files when no longer needed }\end{array}$ & $\begin{array}{l}\text { Unit SOPs for folders and file } \\
\text { naming are lacking or ignored. } \\
\text { File naming and folder } \\
\text { structure are not standard } \\
\text { across the TF. Purging } \\
\text { seldom occurs. }\end{array}$ \\
\hline $\begin{array}{l}\text { Disseminate } \\
\text { messages/graphics - } \\
\text { to bulld complete COP }\end{array}$ & $\begin{array}{l}\text { - Orders are disseminated via FBCB2 } \\
\text { - Digital overlays are disseminated via MDL } \\
\text { - Complete dissemination occurs on first attempt } \\
\text { - Users save files in proper folders } \\
\text { - Users retrieve information readily } \\
\text { - Correct overlays are posted on all platforms }\end{array}$ & $\begin{array}{l}\text { Leaders fail to detect } \\
\text { incomplete dissemination of } \\
\text { messages/overlays. Users fail } \\
\text { to save materials properly and } \\
\text { have trouble retrieving desired } \\
\text { information. }\end{array}$ \\
\hline $\begin{array}{l}\text { Confirm receipt of } \\
\text { critical messages - to } \\
\text { assure complete } \\
\text { dissemination }\end{array}$ & $\begin{array}{l}\text { - TACSOP specifies confirmation process } \\
\text { - Leaders track message reception status } \\
\text { - Recipients send messages verifying receipt } \\
\text { - Leaders relay status reports higher } \\
\text { - All users have essential messages prior to LD }\end{array}$ & $\begin{array}{l}\text { SOPs ignore confirmation. } \\
\text { Critical messages fail to } \\
\text { require operator response. } \\
\text { Platforms end up missing } \\
\text { essential information. }\end{array}$ \\
\hline \multicolumn{3}{|c|}{ Force Mobility and Maneuver } \\
\hline $\begin{array}{l}\text { Use FBCB2 to plan and } \\
\text { execute movements - } \\
\text { to increase speed and } \\
\text { precision }\end{array}$ & $\begin{array}{l}\text { - Current operational graphics are posted } \\
\text { - Current obstacle overlays are posted } \\
\text { - LOS and Nav tools are used to select routes } \\
\text { - CLOS tool reveals vulnerable areas of route } \\
\text { - Hazardous areas and chokepoints are identified } \\
\text { - Leaders disseminate route maps as overlays } \\
\text { - Leaders confirm reception of route information } \\
\text { - Users save route strip maps as overlays } \\
\text { - Drivers use route strip maps to navigate } \\
\text { - Elements navigate safely, accurately, quickly }\end{array}$ & $\begin{array}{l}\text { Lack of wargaming can leave } \\
\text { movement problems (choke } \\
\text { points, danger zones, etc.) } \\
\text { unresolved. Users neither } \\
\text { save overlays properly nor } \\
\text { post them to the display. } \\
\text { Leaders fail to save and } \\
\text { disseminate route maps. }\end{array}$ \\
\hline $\begin{array}{l}\text { Leverage FBCB2 in } \\
\text { maneuver decisions - } \\
\text { to enhance BLUFOR } \\
\text { lethality and } \\
\text { survivablity }\end{array}$ & $\begin{array}{l}\text { - Leaders control order/rate of march via FBCB2 } \\
\text { - SA facilitates formation and dispersion } \\
\text { - Leaders track CCIR \& decision points via COP } \\
\text { - Commander uses SA to cue use of UAV } \\
\text { - Geo-reference icons appear in COP } \\
\text { - Leaders monitor breaching and river crossing } \\
\text { - FBCB2 is used to call for precision smoke } \\
\text { - Leaders SPOT traffic flow problems via SA } \\
\text { - FBCB2 influences maneuver decisions }\end{array}$ & $\begin{array}{l}\text { Ignoring SA picture degrades } \\
\text { control of movement. CCIR } \\
\text { and decision points are } \\
\text { tracked poorly. Traffic flow } \\
\text { problems are detected late. }\end{array}$ \\
\hline $\begin{array}{l}\text { Exploit FBCB2 in } \\
\text { fratricide prevention - } \\
\text { to minimize Blue } \\
\text { attrition }\end{array}$ & $\begin{array}{l}\text { - Current operational graphics are posted } \\
\text { - Current obstacle overlays are posted } \\
\text { - Operators set alert filters properly } \\
\text { - Icons appear for non-reporting elements } \\
\text { - Users monitor Blue SA regularly } \\
\text { - Users respond to alerts with appropriate actions } \\
\text { - Elements avoid hazards and danger zones } \\
\text { - Leaders use Blue SA to deny fires } \\
\text { - Net Join occurs when EPLRS servers fail } \\
\text { - S6 periodically checks \# systems reporting to TI } \\
\text { - Degradation of TI is FFIR }\end{array}$ & $\begin{array}{l}\text { Users fail to save and post } \\
\text { overlays properly. Users often } \\
\text { filter out alerts. Icons for } \\
\text { dismounts and recon elements } \\
\text { are not entered. TACSOP fails } \\
\text { to specify procedures when } \\
\text { too few platforms are } \\
\text { reporting. Blue vehicles enter } \\
\text { hazardous areas. }\end{array}$ \\
\hline
\end{tabular}

In packaging the cumulative information as a primer for 4ID leaders, the team developed the format appearing in Table 3. The contents come directly from Tables 1 and 2 . The "Keys to 
Success" represent critical enablers for effective digital operations. "Probability of Exploitation" is based on SME estimates of 4ID usage rates and is intended as a potential indicator of underutilized capabilities. "Exploitation Pitfalls" describe performance deficiencies commonly associated with each capability. The "Says Who?" column summarizes primary evidence for the pitfalls. The complete Leader's Primer for Exploiting FBCB2 is found in Leibrecht et al. (in preparation). The final primer was packaged in an easy-to-read, pocket-sized laminated booklet for dissemination to warfighters.

Table 3

Format of the Leader's Primer

\begin{tabular}{|l|l|l|l|l|}
\hline $\begin{array}{c}\text { FBCB2 } \\
\text { Capabilities- } \\
\text { Tactical Importance }\end{array}$ & \multicolumn{1}{|c|}{ Keys to Success } & $\begin{array}{l}\text { Probability of } \\
\text { Exploitation } \\
\text { Bn--Co/Plt }\end{array}$ & \multicolumn{1}{|c|}{ Exploitation Pitfalls } & \multicolumn{1}{|c|}{ Says Who? } \\
\hline $\begin{array}{l}\text { Establish commo } \\
\text { network - so Blue } \\
\text { picture is accurate }\end{array}$ & $\begin{array}{l}\text { - Radios have correct COMSEC } \\
\text { - All servers are operational } \\
\text { - BLUFOR icons are visible }\end{array}$ & High--High & $\begin{array}{l}\text { Leaders/operators at all } \\
\text { echelons fail to establish } \\
\text { fully functional network }\end{array}$ & $\begin{array}{l}\text { FSRs are often } \\
\text { called to "fix" simple } \\
\text { problems }\end{array}$ \\
\hline $\begin{array}{l}\text { Post obstacle overlays } \\
\text { - to avoid Blue attrition }\end{array}$ & $\begin{array}{l}\text { - Overlays are disseminated } \\
\text { - Users post overlays promptly } \\
\text { - Overlays are updated }\end{array}$ & High----Low & $\begin{array}{l}\text { Co/Plts lose warnings by } \\
\text { failing to post obstacle } \\
\text { overlays }\end{array}$ & $\begin{array}{l}\text { Blue vehicles enter } \\
\text { minefields in NTC } \\
\text { rotations and FTXs }\end{array}$ \\
\hline
\end{tabular}

\section{User Digital Skills and Tasks}

In an important step for defining digital proficiency measurement requirements, the team developed a set of high-priority digital skills and tasks. They accomplished this by translating the major FBCB2 capabilities (from Table 1) into essential user tasks (specific digital actions), consolidating the tasks where appropriate, and organizing the tasks into nine skill categories. The final step was to prioritize the skill categories based on warfighter input and obtain verification by $4 \mathrm{ID}$ leaders and operators. Table 4 displays the resulting skills and tasks.

Table 4

High-Priority FBCB2 User Skills and Tasks

\begin{tabular}{|c|c|}
\hline Skills & Tasks \\
\hline $\begin{array}{l}\text { 1. Perform Precombat Checks and } \\
\text { Inspections }\end{array}$ & $\begin{array}{l}\text { - Perform digital commo check } \\
\text { - } \quad \text { Verify correct COMSEC files in use } \\
\text { - } \quad \text { Clear queues and logs } \\
\text { - } \quad \text { Verify Blue icons on FBCB2 display } \\
\text { - } \quad \text { Maintain awareness of \# vehicles reporting on TI } \\
\text { - } \quad \text { Determine \% FBCB2s reporting on TI } \\
\text { - } \quad \text { Vend critical messages only when comms in place } \\
\text { - Report gaps in Blue SA }\end{array}$ \\
\hline $\begin{array}{l}\text { 2. Disseminate and Manage } \\
\text { Messages and Graphics }\end{array}$ & $\begin{array}{l}\text { - Verify address groups } \\
\text { - Apply FBCB2 to react rapidly to new mission } \\
\text { - Use standard file naming conventions }\end{array}$ \\
\hline
\end{tabular}




\begin{tabular}{|c|c|}
\hline & $\begin{array}{l}\text { - Proactively manage planning process } \\
\text { - Reduce staff planning time (1/3-2/3 rule) } \\
\text { - } \text { - Ensseminate orders and graphics on first attempt } 100 \% \text { dissemination of digital graphics } \\
\text { - Use LOS tool to create sector sketchufire plan }\end{array}$ \\
\hline 3. Plan and Execute Movements & $\begin{array}{l}\text { - Plan/wargame COAs using FBCB2 capabilities } \\
\text { - Select routes using Navigation and LOS tools } \\
\text { - Check filters for audio and visual alerts } \\
\text { - Navigate safely and accurately using FBCB2 } \\
\text { - Conduct breach operations using FBCB2 }\end{array}$ \\
\hline $\begin{array}{l}\text { 4. Apply Situational Understanding in } \\
\text { Maneuver Decisions }\end{array}$ & $\begin{array}{l}\text { - } \quad \text { Post danger zones on operational graphics } \\
\text { - } \quad \text { Ase FBCB2 graphics and SA to maneuver } \\
\text { - Apply SU in tracking decision points } \\
\text { - Use FBCB2 to decide when to deny fires } \\
\end{array}$ \\
\hline 5. Conduct Collaborative Planning & $\begin{array}{l}\text { - Wargame using digital systems in TOC } \\
\text { - } \quad \text { Disseminate latest overlays via MDL } \\
\text { - Perform digital rehearsal } \\
\end{array}$ \\
\hline $\begin{array}{l}\text { 6. Support Logistical Preparations } \\
\text { Unit-Wide }\end{array}$ & $\begin{array}{l}\text { - } \quad \text { Disseminate CSS overlay with OPORD } \\
\text { - } \quad \text { Senform digital CSS rehearsal } \\
\text { - Send up PERIL-based LOGSTAT } \\
\text { - Use FBCB2 to determine logistical status of unit } \\
\text { - Utilize Supply Point icon } \\
\text { - Use Navigation Tool or SA for resupply missions }\end{array}$ \\
\hline 7. Control Indirect Fires & $\begin{array}{l}\text { - Properly route CFFs to supporting AFATDS } \\
\text { - Use pre-planned CFF linked to Quick Send }\end{array}$ \\
\hline 8. Avoid Fratricidal Situations & $\begin{array}{l}\text { - } \quad \text { Pisseminate and update obstacle overlay } \\
\text { - } \quad \text { Create manual icons } \\
\text { - Mpply SPOT reporting and handoff procedures } \\
\text { - Maintain command awareness of platforms on TI }\end{array}$ \\
\hline $\begin{array}{l}\text { 9. Employ Filter Settings to Create } \\
\text { Operational Picture }\end{array}$ & $\begin{array}{l}\text { - Use collapse/expand function } \\
\text { - Uchieve desired operating picture } \\
\text { - Use Center of Mass function }\end{array}$ \\
\hline
\end{tabular}

The user skills in Table 4 were driven primarily by $4 \mathrm{DD}$ operational mission requirements, not by the organization of FBCB2 capabilities. Thus the skills should link closely with mission essential tasks as encountered in a Force XXI unit. This important linkage enables the skills to serve as a valid foundation for developing digital skills proficiency requirements.

Two of the high-priority skills are enablers (i.e., prerequisites underpinning essential combat functions): perform precombat checks and inspections, and employ filter settings to create the operational picture. The remaining skills (e.g., control indirect fires) directly support performance of key battlefield functions that must occur for successful tactical operations. All of the skills, in a sense, constitute higher order applications of digital capabilities-each skill harnessing multiple FBCB2 features to accomplish functional performance requirements. 
The nine high-priority user skills, with their informal validation by 4ID warfighters, set the stage for focusing digital training objectives and the associated proficiency measurement requirements. They define high-payoff performance dimensions around which to structure observation and assessment activities of trainers and observers. The consensus priorities provide a loose framework for weighting the value of various proficiency measures, but they should be interpreted with professional judgment and common sense.

The user skills and tasks presented in this section establish a manageable set of digital performance dimensions for allocating the attention and effort of training observers. They also provide a useful basis for shaping unit training programs and leaders' assessment tools. In the FBCB2-TFV project, the "top nine" skills formed the foundation for developing digital observation guidelines in the Exploitation Tool (discussed below in the Interim Observation Guidelines Section).

\section{Network Management Skills}

The TI is comprised of a lower TI and an upper TI (the latter is called Warfighter Information Network-Terrestrial, or WIN-T). The lower TI connects ABCS components with Embedded Battle Command (EBC), Mobile Subscriber Equipment (MSE), and the Near Term Digital Radio (NTDR). The lower TI consists of FBCB2, Enhanced Position Location Reporting System (EPLRS), Single Channel Ground and Airborne Radio System (SINCGARS), and internet controllers (INCs). Critical to the entire TI are the carrier sense multiple access (CSMA) servers. They link each battalion to the rest of the brigade. Each maneuver battalion has nine EPLRS-equipped platforms that are the designated CSMA servers. These servers, also called SA (Situational Awareness) servers, broadcast the battalion's SA picture to the rest of the brigade via an EPLRS logical channel network (LCN). This LCN is resident on all EPLRS systems in the brigade. However, only the SA servers transmit on this "brigade-wide" LCN. The rest of the EPLRS simply receive the broadcast and enable displaying the SA from outside the battalion.

For the purposes of this report, the team focused on the lower TI and the FBCB2-related TI responsibilities of the users/leaders in their FBCB2-equipped platforms as well as the Signal Officer (S6) in the TOC. Unit/leader responsibilities include being aware of ga:ss in the Blue picture, ensuring the communication equipment is connected properly, and verifyin: they have the correct communications security (COMSEC) loads. Users must detect problems with the lower TI and initiate troubleshooting techniques such as verifying EPLRS server functionality and executing a Net Join if needed.

The analog TOC differs greatly from the digital TOC. Gone are the days where the most critical piece of communications equipment was the FM radio. Today's digital staff officers must apply their digital knowledge to the traditional analog TOC operations. The traditional TOC had each staff section monitoring radio nets and updating the commander verbally and on the map board. Today's digital TOC still possesses the analog tools but is further complicated with simultaneous real time information from each section and higher echelons. The digital staff officers must be knowledgeable in the operation of their digital systems and, just as important, sort through the large amounts of information the systems provide. 
The foundation for successful digital operations is a well-managed TI. Without that, digital operations will fail. The task force S6 is responsible for ensuring the network is healthy. He monitors the lower (FBCB2) TI through the Tactical Internet Manager System (TIMS). The TIM software can be tailored to provide feedback on the number of platforms operational, key nodes operational, SINCGARS operational servers, EPLRS radio operation, NTDR links to the flanking brigade, and status of SA servers. Just as there is a need to measure proficiency of FBCB2 users and operators, there is also a need to measure the proficiency of the network manager.

Table 5 lists some high-priority network skills that, when measured, can provide leaders and trainers information on the proficiency of network managers.

Table 5

High Priority Network Management Skills (Lower TI)

\begin{tabular}{|c|c|}
\hline Network Manager Skill & Critical Network Query \\
\hline $\begin{array}{l}\text { Verify Task Force Situational } \\
\text { Awareness }\end{array}$ & $\begin{array}{l}\text { - Is SA server active? } \\
\text { - Are flanking TFs and Bde troops in the TF SA picture? } \\
\text { - Are all platforms on correct UTR? } \\
\text { Can all TF platforms see the correlated Red picture from } \\
\text { ASAS? }\end{array}$ \\
\hline $\begin{array}{l}\text { Verify Task Force Command and } \\
\text { Control }\end{array}$ & $\begin{array}{l}\text { - Did Co Cdrs and special PIt Ldrs receive TF graphics? } \\
\text { - Did all companies receive correct message address groups? } \\
\text { - Did all companies receive tailored CTIL from the S4/CTCP? }\end{array}$ \\
\hline Verify Task Force FBCB2 Security & $\begin{array}{l}\text { - Are all FBCB2 platforms operating at the appropriate } \\
\text { security level? }\end{array}$ \\
\hline
\end{tabular}

\section{Factors Influencing Digital Performance}

\section{Echelon and Mission Phase}

The team initially identified two important factors related to the frequency of application and the exploitation of FBCB2. These two factors were echelon and type of mission. As the analysis proceeded, it became clear that the type of mission-attack, defend, movement to contact-was not as important as initially thought. The team discerned that the application and frequency of use related more closely to the phase of the mission. In examining mission phases-planning, preparation, and execution-the team found that the higher echelons (staff in TOC) depended on the FBCB2-provided Blue SA more during the execution phase than did lower echelons. It was crucial to command and control at the battalion level. During mission execution, leaders at lower echelons are looking outside the hatch, and they can usually see their subordinate elements.

The battalion leadership was more likely to set their filters to develop their desired view of the battlefield, especially during the execution phase. This echelon also used FBCB2 during the close fight to observe the ongoing battle, receive real time feedback, and make decisions 
based on the SA. The leadership was also much more reliant on FBCB2 for command and control during nighttime operations or operations that required close monitoring, such as breaching operations.

In comparison, the lower echelons depended on FBCB2 primarily during the planning and preparation phases. Below the company command echelon, platform operators were more consumed with reacting to the battle than with monitoring and applying their FBCB2. The maneuver company and platoon leadership used FBCB2 in their decision-making process more during the planning and preparation phases than during the execution phase. The planning and preparation phases were more conducive to company/platoon application of FBCB2, especially for reconnaissance, observation of the enemy, and plan adjustment. For example, reconnaissance elements rely heavily on FBCB2 for map reconnaissance, terrain information, and All Source Analysis System (ASAS)-reported enemy locations in their correlated Red picture. Once the reconnaissance elements locate the reported enemy, they can keep "eyes on" and help maintain the current Red picture. This current Red picture helps commanders determine if their maneuver plan needs to be adjusted.

The more engaged the operators became in waging the fight, the less they relied on FBCB2. Many said the only time they referred to FBCB2 during the battle was for the SA picture. This mentality changed if the battle occurred at night or through very difficult terrain. At those times users depended on FBCB2 for SA of the Blue force and, more specifically, the navigation features.

\section{Unit Standing Operating Procedures (SOPs)}

Tactical units rely on SOPs to detail warfighting practices and conventions that all elements should follow. For digital operations, unit SOPs play a critical role in specifying the procedures for employing and exploiting the FBCB2 and other digital systems. The SOPs should procedurally link specific digital capabilities with basic tactical procedures. For example, operators and users need to know when/how they are expected to relay digital SPOT reports of enemy sightings and how to manage the updating of those icons. In an important sense, the guidance contained in SOPs shapes the sender and receiver expectations for digital communications-cornerstone aspects of digital proficiency. The SOPs can also convey why it is important to use the digital capabilities. Further, procedural standards point to key targets for digital proficiency measurement. Ultimately unit-generated digital SOPs can become incorporated in TTPs used across the Army.

Force XXI warfighters have consistently reported that digital SOPs are very important for successful digital operations (e.g., Dudley et al., 2001). In the Army's groundbreaking digitization environment, a heavy burden fell on the shoulders of unit leaders to document how digital capabilities can be used and exploited, then incorporate the discoveries and lessons learned in the unit SOPs. The discovery and documentation process is progressive. For example, once units start reporting and posting enemy sightings via digital SPOT reports, the specifics of managing Red icons come into play. What changes in the Red situation should trigger updating of Red icons? How are updated Red icons to be detected and interpreted 
throughout the unit? What happens if the initial reporter of the enemy has to move? The progressive process means that SOPs must be updated frequently.

Because SOPs define performance expectations, they would be expected to heavily influence digital performance. However, units have found it difficult to establish and maintain digital SOPs in the press of numerous high-priority demands on their time. Units are not adequately resourced to document digital procedures in SOPs. Thus unit SOPs have been slow to incorporate digital procedures. There also has been no organized and effective mechanism to transfer lessons learned and SOPs from experienced units to those just receiving digital systems. As a result, the potential for unit SOPs to shape digital performance awaits realization.

\section{Task Difficulty}

The team interviewed soldiers upon their completion of Key Leader's Training at the BCTC. With the training fresh in their minds, the soldiers could readily identify FBCB2 tasks that were in the "too hard to do" category. None of the soldiers and leaders interviewed felt that any of the FBCB2 applications were mentally too difficult to execute. They defined a task as "too hard" if it took too many keystrokes to accomplish. If the desired outcome took too long to achieve, the users did not pursue it. Some of the more common high-difficulty tasks are:

- Creating and retrieving overlays

- Using the navigation function

- Creating preformatted messages

- Executing a Net Join

These skills may be perceived as too hard to do during operations as most require more than three keystrokes to get to the desired end result. If users are under the pressures associated with combat, they probably will not attempt functions that are too time consuming or not executed on a regular basis. In the chaos of combat, soldiers desire immediate response to information needs. They also revert back to the analog procedures to which they are more accustomed. As documented in previous ARI reports (Elliot, Sanders, and Quinkert, 1996; Sanders, 1999), digital skills decay if not used regularly. Therefore, any task that is too cumbersome to execute will likely result in degraded skill proficiency.

Overlay creation is a time consuming process. One cause of frustration results from placing all Army standardized map symbols in a drop-down menu for selection. The user has to scroll through the list to find the correct symbol for the overlay. It is a tedious process to select the location on the map where the symbol goes, then orient the symbol in the proper direction, and change the color if so desired.

Units continue to struggle with finding the most recently received overlay, order, or message. When messages are shown in the flash-immediate-priority-routine (FIPR) queue, the message type is generic. For example, the engineer obstacle overlay is titled "obstacle." It does not tell the user the operations order to which the overlay pertains. File naming conventions are taught in the FBCB2 Key Leader's Course, where the user learns how to name the message as he saves it and then file it in a message folder he must create. 
The Navigation tool has numerous steps for users who desire to build a strip map, use the route analysis function, or just keep the route displayed on the driver's screen. It is extremely helpful when maneuvering at night or in situations where visibility is limited. Instead of employing the tool, users typically apply the "center on" function. This function allows the operator to select a location that will remain at the center of the FBCB2 display regardless of the platform's own location. Drivers simply "center on" a location and drive to it. This method, while not as effective, is faster.

Preformatted messages were the result of User's Jury comments made during FBCB2 development. They are meant to expedite the creation of standard messages (for example, nuclear, biological, chemical (NBC) reports, SPOT reports, medical evacuation [MEDEVAC] requests). Using drop-down menus to enter information was thought to be easier, especially if the vehicle is on the move. However, the creators of messages become frustrated when they cannot edit the text or enter free text.

Not all FBCB2 platforms are EPLRS servers. For example, in a tank platoon of four vehicles, two vehicles (the platoon leader and platoon sergeant) host EPLRS servers. When these vehicles are eliminated from the platoon, the remaining vehicles have no server to transmit their data to the lower TI. The surviving vehicles must then perform a Net Join to link with a new communications hub so they receive information and transmit SA data via the lower TI.

Training is essential if users are to exploit the high-difficulty skills discussed above. These skills should be trained and reinforced in the classroom, in simulation exercises, and in the field. Their employment can result in faster, more informed decisions and, in the case of Net Join, may be key in preventing fratricide.

\section{Performance Problems}

In the FBCB2 environment there are various sources of digital performance problems. Problems may stem from the misapplication of FBCB2 capabilities, the lack of training, the unavailability of SOPs, the lack of appropriate feedback, and inexperience. Problems at one echelon may not occur at another. In this section, we focus on the lowest level of performance problems - the operator level. The FBCB2 is the cornerstone of the digital battlefield. No matter how proficient the staff, if the FBCB2 operators do not employ their systems as intended the COP will not be a true picture. The Red and Blue pictures will be incomplete.

The primary evidence of FBCB2 operator performance problems was found in reports and interviews from FSRs who supported units at Fort Hood. The FSRs were government contractors assigned to each unit for technical support. The majority of the problems reported by FSRs stemmed from lack of sustainment training and/or failure to apply troubleshooting procedures.

Units need to be innovative in incorporating digital training into their training schedules. One recommendation made by a senior FSR was to conduct weekly connectivity exercises during motor pool maintenance. As part of vehicle preventive maintenance checks and services (PMCS), operators could load the correct COMSEC fill into their SINCGARS and EPLRS 
systems, and turn on the FBCB2, Precision Lightweight GPS Receiver (PLGR), NC, and radios. While completing PMCS, the FBCB2 would go through its booting sequence. Once the PMCS was complete, the soldiers could then ensure proper connectivity on the appropriate SINCGARS hopsets and EPLRS network. Once connectivity was verified the operators could conduct both SA and command and control tasks. For instance, all vehicles would ensure they could see other icons in their battalion and ensure they could be seen by other platforms. If there were connectivity problems, operators would conduct the appropriate troubleshooting procedures found in the FBCB2 operator's manual. As part of verifying command and control connectivity, all platforms would send an overlay message, a free text message, and a SPOT report.

This simple exercise would also address another weak area the FSRs encounteredtroubleshooting procedures. The FSRs attributed many of the FBCB2 performance problems to the lack of troubleshooting. Even though troubleshooting procedures are listed in the operator's manuals, most often soldiers merely notify their $31 \mathrm{U}$ (unit signal Support Systems Specialist) when a problem occurs. This can lead to delays because there is only one $31 \mathrm{U}$ in each company. Examples of some of the most common performance problems are revealing: (a) FBCB2 systems are simply not turned on; (b) cables are unconnected, improperly connected or missing; (c) radios have no COMSEC fill or an improper COMSEC fill loaded; (d) PLGRs are not connected; and (e) INCs are not turned on. Such problems involve simple fixes that, if corrected, mean the difference between a digital network that is fully mission capable and one that is not.

The weekly connectivity exercise would produce benefits in multiple areas-identifying faulty hardware, reducing the surge of equipment exchanges during field exercises, and maintaining basic FBCB2 operator skills by virtue of routine sustainment training.

Another vital means for establishing and maintaining digital performance is the creation and application of digital SOPs, discussed above under Factors Influencing Digital Performance. When queried about the unit's digital SOP, most warfighters interviewed in this project admitted they did not have one but needed it. They identified the unit's high operational tempo as the reason digital SOPs had not been created.

The findings on FBCB2 performance problems and high-difficulty tasks indicate the importance of prioritizing FBCB2 training and observation needs. Just as important is the need to create digital SOPs and incorporate FBCB2 tasks into unit training schedules on a regular basis.

\section{Indicators of Digital Proficiency}

\section{Measurement Implications}

Measurement of digital skills proficiency is indispensable if units are to improve their performance with the aid of C4I tools. Effective digital training demands achievable, operationally anchored feedback on how well individuals and units are exploiting their digital capabilities. Failure to measure and assess digital skills proficiency ensures that units will fall seriously short of their combat effectiveness potential-most likely without realizing it. At the same time, measuring digital proficiency must be managed and tailored to optimize the 
efficiency and effectiveness of the performance assessment process. In large part, optimizing the assessment process means focusing on high-payoff proficiency targets. This, in turn, contributes greatly to optimizing the training value, or retum on investment, achieved by the units.

High-payoff digital skills are those that contribute most critically to tactical performance. The high-priority FBCB2 user skills identified in this project (Table 4) can serve as a spotlight to focus the attention of observers and the entire feedback process. These skills, along with their associated tasks, define the digital performance dimensions that most warrant the attention of trainers and observers. The high-payoff skills spawn measures of digital proficiency (see Interim Observation Guidelines, below) that can optimize the performance assessment process and AAR feedback procedures. In the bargain, focusing on top priority user skills can reduce observer workload and enhance training payoff.

Levels of digital proficiency play a key role in assessing performance. For each of the implementing actions associated with an FBCB2 user skill, levels of proficiency can be defined as performance benchmarks. Meliza (in preparation) detailed working levels of proficiency for seven clusters of digital skills as well as fifteen "diagnostic" indicators of overall proficiency. Consider the case of "Taking actions to ensure connectivity" as an example. In this case, Meliza spelled out proficiency levels ranging from "unit is unaware of degree of connectivity maintained during the last exercise" (low proficiency) to "ability to troubleshoot and address most connectivity problems" (high proficiency). One advantage of such benchmarks is their preexercise utility for tailoring both training and feedback. An additional advantage is that most of the indicators of digital proficiency can be applied by simply asking questions of unit members (e.g., does your unit have an SOP for naming different versions of obstacle overlays?) Future efforts may be desired to develop proficiency benchmarks for the top nine FBCB2 user skills.

The training and feedback needs of a unit depend on a host of factors including echelon of the training audience, specific training objectives, the unit's pre-exercise level of proficiency, and designated areas needing emphasis. To meet the diversity of needs, trainers and observers should be prepared to tailor each training exercise, especially the observation and feedback procedures, to optimize the training experience. The high-payoff user skills identified in this project provide a sound basis for tailoring FBCB2-oriented training objectives/methods and the performance assessment procedures. Such tailoring can enhance the ability of the observers to provide high-payoff feedback, reduce the workload of the observers, and boost the performance improvement realized by the unit.

For tailoring observation and feedback during FBCB2 training exercises, several factors discussed in the preceding Factors Influencing Digital Performance section are valuable. The findings suggest a practical means for focusing an observer's attention and effort. At company level and below, observers can concentrate on a narrower set of digital capabilities, at the same time allocating greater attention to proper connectivity, threat tracking, fire support, disseminating messages/graphics, and preventing fratricide. Mission planning and preparation phases will generally afford more opportunities to observe FBCB2 skills in action, especially at company echelon and below. More difficult digital tasks (e.g., using navigation tools, creating overlays, performing Net Join) may require greater attention in AARs, even if warfighters tend to ignore those tasks during the exercise. When operations involve limited visibility or difficult 
terrain, digital skills supporting navigation will likely merit special attention. Finally, knowing a unit's overall level of experience or proficiency beforehand will help observers decide whether to focus on basic digital skills or more advanced applications (Meliza, in preparation).

A number of measurement approaches and techniques are available for measuring digital skills proficiency. In earlier work, Dudley et al. (2002) analyzed the measurement needs for digital skills associated with preventing fratricide and controlling enemy contact. They concluded that all-or-none (go/no go) or simple graduated (trained/needs practice/untrained) approaches are suitable for a range of needs. They determined that the suitability of the two approaches depends on task criticality, task complexity, and performance time span. For the user digital skills that emerged in the FBCB2-TFV project, four primary techniques are envisioned for measuring proficiency. These include examination of digital message traffic, investigation of user-system interactions, inspection of platform status or usage, and self-report by operators or users. In addition to manual procedures, automated tools could be leveraged in support of all four techniques. In this ongoing research program, development of performance measures and procedures has been reserved for future work.

Specific applications of measurement techniques will be outlined below in the discussion of Interim Observation Guidelines. As noted in the foregoing paragraphs, additional research is needed to systematically develop working tools and procedures as part of a comprehensive architecture for measuring digital proficiency.

\section{Interim Observation Guidelines}

Establishing interim observation guidelines for FBCB2 trainers constituted an important objective of the project. The team produced a user-friendly Exploitation Tool to focus measurement activities and facilitate high-payoff performance feedback. The ultimate goals were to (a) provide a guide for leaders to gauge the digital proficiency of their units, (b) optimize the training value realized by digital units, and (c) reduce the overall workload of exercise observers.

The matrix format of the FBCB2 Exploitation Tool is designed for easy reference and tracking by digital observers and trainers. For each of the nine high-priority digital skills (from Table 4), the matrix contains four columns of practical information (see Table 6). Performance goals correspond to the tasks appearing in Table 4 and point to fairly specific system-oriented steps. The echelon column indicates the echelon(s) to which each performance goal appliesbattalion and below for this project. Trigger information specifies the timeframe or condition(s) that normally prompt the performance of digital tasks. The final column identifies procedures for obtaining relevant performance data. The various types of data include (a) digital message traffic (as viewed on system displays), (b) user-system interaction (as observed in real time), (c) platform status or usage (as observed on system displays), and (d) self-reported performance of digital actions (warfighter responses to questions). Altogether, the tool provides concise instructions on what performance data to collect, and when, where, and how to collect it. A companion report (Leibrecht et al., in preparation) contains the complete Exploitation Tool. 
Table 6

Matrix Format of FBCB2 Exploitation Tool, with Sample Entries

\begin{tabular}{|c|c|c|c|c|}
\hline Skill & $\begin{array}{l}\text { Performance } \\
\text { Goals }\end{array}$ & Echelon & Trigger & Where to Find Data \\
\hline \multirow[t]{2}{*}{$\begin{array}{l}\text { Precombat } \\
\text { Checks/ } \\
\text { Precombat } \\
\text { Inspections } \\
\text { (PCC/PCI) }\end{array}$} & $\begin{array}{l}\text { Report gaps in } \\
\text { Blue SA to } \\
\text { higher \& lower } \\
\text { HQ, alerting } \\
\text { network to } \\
\text { degraded COP }\end{array}$ & $\begin{array}{l}\text { - Battalion } \\
\text { - Company } \\
\text { - Platoon } \\
\text { - Platform }\end{array}$ & $\begin{array}{l}\text { User } \\
\text { realizes } \\
\text { Blue } \\
\text { picture is } \\
\text { degraded } \\
\text { (not due to } \\
\text { his filter } \\
\text { settings) }\end{array}$ & $\begin{array}{l}\text { View User-System Interaction: } \\
\text { - User performs troubleshooting to rule out problems } \\
\text { with his platform (i.e., verifies current COMSEC, } \\
\text { verifies EPLRS server is operational, checks filter } \\
\text { settings) } \\
\text { Observe Platform Data: } \\
\text { - Did user take the initiative and enter Blue icons to } \\
\text { prevent fratricide? } \\
\text { Query Warfighters: } \\
\text { - Was correct COMSEC loaded? } \\
\text { - Was notification of any blue SA gaps made network } \\
\text { wide to avoid fratricide? }\end{array}$ \\
\hline & $\begin{array}{l}\text { Clear queues } \\
\text { and logs to } \\
\text { speed up } \\
\text { refresh rate, } \\
\text { resulting in } \\
\text { more accurate } \\
\text { and timely } \\
\text { COP }\end{array}$ & $\begin{array}{l}\text { - Battalion } \\
\text { - Company } \\
\text { - Platoon } \\
\text { - Operator }\end{array}$ & $\begin{array}{l}\text { When } \\
\text { refresh } \\
\text { rate slows; } \\
\text { at a } \\
\text { minimum, } \\
\text { prior to } \\
\text { new } \\
\text { mission }\end{array}$ & $\begin{array}{l}\text { Observe User-System Interaction: } \\
\text { - Note if system refresh rate is visibly slow } \\
\text { - View message cut to determine last time it was } \\
\text { cleared } \\
\text { Query Warfighters: } \\
\text { - Ask commanders and operators when/how often } \\
\text { they cleared their queues and logs before and during } \\
\text { the mission }\end{array}$ \\
\hline
\end{tabular}

The matrix tool is designed to guide the planning and execution of assessment activities by observers supporting FBCB2 training exercises. It can assist observers in live, virtual, and constructive training environments, but obtaining performance data is generally easier in simulation environments. The guide focuses performance assessment efforts on high-value skills and tasks that especially contribute to overall combat effectiveness. In turn this enhances the feedback and AAR process. By emphasizing high-payoff feedback in the hands of training support personnel, the guide helps units get the greatest return from their digital training exercises. In the process it helps observers achieve economy of effort and manage a potentially overwhelming workload. Finally, it provides a valuable tool for leaders to gauge the digital proficiency of their units and identify realistic training needs.

During the course of the project, the FBCB2 Exploitation Tool was used during battalion training exercises in CCTT. The limited feedback indicates the format and contents are wellsuited for operational training. The matrix encapsulates what-where-when-how guidelines in a concise, easy-to-use package that fits all echelons and missions. As a process guide it fosters insight and resourcefulness on the part of observers. As a commander's assessment tool it offers a systematic framework for training to a level of digital proficiency that directly enhances combat effectiveness. The potential utility and value of the tool warrants further application and development. 


\section{AAR Implications}

This effort is the first attempt to provide observers of digital training a measurement guide so there is a standard digital proficiency goal for units to achieve. The systems and software are evolving. Our objective was to enable feedback that is not tied to specific software functionality. Another goal was to provide evaluators with a measurement tool that might transcend their own digital expertise or lack thereof.

Feedback is essential during operations and during AARs. The Exploitation Tool matrix presented by Leibrecht et al. (in preparation) focuses on the user's abilities during operations. It provides detailed questions the observer can ask of operators and users to ascertain their digital knowledge. Most of the AARs the research team observed following digital exercises focused on how the unit performed tactically, not how well the unit applied the digital tools in support of the mission. Having structured AAR tools can keep the process focused on the digital aspects of the operation (when needed). Table 7 contains high-priority questions related to FBCB2 operations that an observer can ask during an AAR to shift attention to exploiting FBCB2 capabilities. In addition, each of the "query warfighter" items in the Exploitation Tool can be used as a question during AARs.

Table 7

AAR Questions for Shifting the Spotlight to FBCB2 Exploitation

\begin{tabular}{|l|}
\hline 1. How did your use of FBCB2 impact your mission execution? Consider the digital \\
information you received and how it affected your ability to execute actions.
\end{tabular}




\section{CONCLUSIONS AND RECOMMENDATIONS}

\section{Conclusions}

The overarching purpose of the FBCB2-TFV research project was to develop a basic architecture for measuring digital skills proficiency. The project pursued three principal goals: (a) characterize major tactical performance dimensions of FBCB2 utilization, including user skills; (b) examine key factors influencing digital performance; and (c) establish detailed guidelines for measuring high-payoff FBCB2 user tasks. The products of the research establish tools and knowledge that can be used to tailor digital training, enhance the efficiency and effectiveness of digital feedback processes, and boost the overall payoff of digital training programs.

Measuring digital skills proficiency is essential if units are to achieve the performance potential of advanced C4I tools. The current project contributed significantly to tools for assessing how well individuals and units are exploiting their digital capabilities. The results advance the state of the art for measuring digital proficiency thus helping trainers and observers to work smart and focus their efforts on high-payoff skills. Collectively the findings establish an initial digital proficiency architecture for units employing the FBCB2.

The recurring patterns and critical insights presented in this report are of primary value where leaders, trainers, and observers are working to prepare realistically for FBCB2-supported combat operations. Although centered deliberately around the FBCB2 and the $4 \mathrm{ID}$, the findings may suggest approaches for assessing performance where other digital systems and units are involved.

Based on their role in achieving unit effectiveness, 21 major FBCB2 capabilities emerged as major contributors. They fall in five functional categories: digital basics, battlefield visualization, mission planning and preparation, tactical information exchange, and force mobility and maneuver.

The Leader's Primer for Exploiting FBCB2 provides concise informatio' to focus unit leaders and others on high-payoff proficiency targets. It inventories digital keys to tactical success, along with indicators of under-utilized capabilities and performance pitfalls. The guide can support a commander's assessment of his unit's digital proficiency.

The frequency with which units employ the major FBCB2 capabilities varies by type of function-planning and command and control functions are more frequent, while housekeeping and analytical functions are less frequent. Frequency of employment also varies by echelon, with battalion personnel using most capabilities more often than lower echelons, especially during the execution phase.

Nine FBCB2 user skills emerged as high-payoff targets, encompassing 50 FBCB2 performance goals. Linked to mission essential tasks, the nine skills support valid skills proficiency measurement and provide a basis for focusing observation and assessment efforts. In descending order of priority, the high-payoff skills are: 
1. Perform Precombat Checks and Inspections

2. Disseminate and Manage Messages and Graphics

3. Plan and Execute Movements

4. Apply Situational Understanding in Maneuver Decisions

5. Conduct Collaborative Planning

6. Support Logistical Preparations Unit-Wide

7. Control Indirect Fires

8. Avoid Fratricidal Situations

9. Employ Filter Settings to Create Operational Picture

Given the importance of a fully functional TI to enable and sustain digital operations, network management skills are major contributors to digital proficiency. Three high-priority TI management skills were identified:

1. Verify Task Force Situational Awareness

2. Verify Task Force Command and Control

3. Verify Task Force FBCB2 Security

Unit SOPs at the battalion level and below do not generally describe digital activities in sufficient detail to shape expectations of digital skills performance. To date the SOPs lack the maturity to specify acceptable levels of unit digital proficiency. The process for establishing and updating digital SOPs is not resourced. An important goal for the future force should be to ensure that comprehensive unit SOPs are developed and maintained, as a cornerstone for defining and standardizing digital proficiency expectations.

Among the factors influencing digital performance are echelon, mission phase, and task difficulty. Battlefield conditions, especially limited visibility and difficult terrain, also affect performance. Echelon and mission phase interact in their effects on performance. Warfighters define task difficulty in terms of complexity (number of keystrokes required) and/or time required to perform the task. The most common denominator for gauging performance effects is frequency of use.

It is difficult to investigate the impact of level of digital experience on performance, especially considering the lack of formal system training, the absence of digital procedures in unit SOPs, and the paucity of digital measures of performance. As digital training and standards expand, more rigorous research methods can be applied to study the role of experience level.

The general techniques required for measuring digital skills proficiency understandably focus on utilizing system capabilities. The primary techniques include examination of digital message traffic, observation of user-system interactions, inspection of platform status or usage, and self-report by operators and users.

The compact FBCB2 Exploitation Tool provides interim observation guidelines in userfriendly form. The matrix readily supports convenient referencing and tracking by exercise observers, with detailed instructions for collecting performance data. The tool also can serve as a proficiency assessment guide for unit leaders. 
The outcomes of this project, especially the Leader's Primer and the Exploitation Tool, are expected to directly benefit digital units throughout the Army as well as their training support elements. Among the projected benefits are:

- Enhancement of products supporting brigade operations and training, such as unit SOPs and training support packages.

- Guidance for evaluating key FBCB2 operator/user skills, covering various echelons and training environments.

- Approaches and techniques for improving digital feedback tools and shifting the AAR focus to exploiting the power of digital systems.

- Knowledge base for improving training effectiveness and reducing observer workload.

- Sharing of hard-won warfighter knowledge and insights so that valuable information is preserved and disseminated.

Continuing research is essential to build a comprehensive digital proficiency architecture, expand the knowledge base to encompass the current and future force, develop specialized measurement/feedback techniques and tools, and validate new or improved assessment methods and procedures.

\section{Recommendations}

The findings of this project address the proficiency measurement needs of FBCB2equipped units. Extensive work lies ahead to expand the digital proficiency architecture and tools so they can fully support training programs of the current and future force. The authors offer the following recommendations:

- Emphasize and resource the development and maintenance of digital procedures as a required component of unit SOPs.

- Expand the knowledge base to include the measurement and feedback needs of ATCCS-equipped units/elements, interim forces, and the Objective Force.

- Describe proficiency levels and indicators for system-specific digital performance across a variety of units and echelons.

- Develop and validate observation guidelines for battle staffs, Combat Support units, and Combat Service Support units.

- Develop and validate commander's assessment tools for gauging the proficiency and training needs of units and battle staffs.

- Investigate how key factors (e.g., echelon, mission parameters, task difficulty, level of experience, battlefield conditions) influence digital performance.

- Design and develop automated techniques and tools for measuring digital skills proficiency and for leveraging high-payoff feedback in AARs.

- Evaluate the utility and effectiveness of alternative approaches for measuring digital skills proficiency in operational settings.

- Establish a digital training laboratory to support the systematic investigation of Objective Force performance and proficiency assessment needs.

The research findings of the FBCB2-TFV project establish an initial architecture for measuring digital skills proficiency. The products of the research establish tools and knowledge 
that can be used to tailor digital training, enhance the efficiency and effectiveness of digital feedback processes, and boost the overall payoff of digital training programs. However, much remains to be learned through follow-on research. Expanding the tools and knowledge is an essential step for optimizing the warfighting proficiency of the Objective Force.

Current efforts of the team are directed toward three objectives. The first objective is to develop guidance for measuring how well a unit exploits C4I systems in the TOC environment, emphasizing battlefield operating system integration. In addition to providing guidance to trainers about what to observe during digital exercises, meeting this objective will involve defining AAR display requirements for training digital staffs. The second objective is to describe ways in which digital proficiency measurement will change or remain the same with the Objective Force. The third is to describe AAR system capabilities that can support current digitized units while providing a foundation for training the Objective Force. 


\section{REFERENCES}

Barnett, J. S., Meliza, L. L., \& McCluskey, M. R. (2001). Defining digital proficiency measurement targets for US Army units (ARI Technical Report 1117). Alexandria, VA: U.S. Army Research Institute for the Behavioral and Social Sciences. (AD A396 899)

Brown, B. R., Anderson, L., Begley II, I. J. \& Meliza, L. L. (1999). Cognitive requirements for information operations training (CRIOT) (ARI Study Report 99-02). Alexandria, VA: U.S. Army Research Institute for the Behavioral and Social Sciences. (AD A365 483)

Brown, B. R., Nordyke, J. W., Gerlock, D. L., Begley, I. J., \& Meliza, L. L. (1998). Training analysis and feedback aids study for live training support (ARI Study Report 98-04). Alexandria, VA: U.S. Army Research Institute for the Behavioral and Social Sciences. (AD A351107)

Dudley, M. G., Hill, R., Johnston, J. C., Jones, W. S., LeGare, M., Leibrecht, B. C., Longoria, K., \& Meliza, L. L. (2002). Measuring digital proficiency: Assessment approaches and echelon considerations (ARI Research Report 1791). Alexandria, VA: U.S. Army Research Institute for the Behavioral and Social Sciences. (AD A405 055)

Dudley, M. G., Johnston, J. C., Jones, W. S., Strauss, C. P., \& Meliza, L. L. (2001). Making the transition from analog to digital warfighting: Changes in unit behavior and knowledge (ARI Research Report 1785). Alexandria, VA: U.S. Army Research Institute for the Behavioral and Social Sciences (AD A397 575)

Elliott, G., Sanders W, and Quinkert, K. A. (1996). Training in a digitized battalion task force: lessons learned and implications for future training. (ARI Research Report 1695). Alexandria, VA: U.S. Army Research Institute for the Behavioral and Social Sciences. (AD A313 293)

Leibrecht, B. C., Lockaby, K. J., \& Meliza, L. L. (in preparation). A practical guide for exploiting FBCB2 capabilities (ARI Research Product). Alexandria, VA: U.S. Army Research Institute for the Behavioral and Social Sciences.

Meliza, L. L. (in preparation). Digital skills and indicators of overall digital proficiency (ARI Technical Report). Alexandria, VA: U.S. Army Research Institute for the Behavioral and Social Sciences.

U.S. Department of the Army (2001). Operations (FM 3-0). Washington, DC: Headquarters, Department of the Army.

Warrior-T (2001a). Digital battle staff task map (TRADOC ST 20-101-5, Draft). Fort Hood, TX: Warrior-T Project Office.

Warrior-T (2001b) Army battle command system (ABCS) smart book overivew version 6.2.x. Fort Hood, TX; Warrior-T Project Office. 
Warrior-T (2002a). Training the digital brigade combat team battle staff (16 April $2002 \mathrm{draft}$ )

- Fort Hood, TX; Warrior-T Project Office

Warrior-T (2002b). Army Battle Command System MCS Workstation Individual Tasks Version 6.2.x (2 Jul 2002 draft). Fort Hood, TX; Warrior-T Project Office.

Warrior-T (2002c). Force XXI battle command brigade and below (FBCB2) operator integrator, and decision maker shared individual tasks supporting ST20-101-5-ABCS (3 Jul 2002 draft). Fort Hood, TX; Warrior-T Project Office. 


\section{APPENDIX A}

\section{Interview Questions for Each Echelon}

Name:

Rank:

Phone:

Position: Date of Assignment to Current Position:

Prior Digital Experience (number and type of FTX/CPXs, duties performed, etc.):

ABCS Specific Training Received to Date:

Email Address:

\section{Platoon Leaders}

1. What rules of thumb do you use for setting your FBCB2 filters?

2. Have you ever used your FBCB2 to (if you have not used the below capabilities, please indicate why):

- Navigate under limited visibility situations?

- Move to a breach point?

- Avoid threat situations like minefields, contaminated areas, firesacks?

- Decide when it is time to transition from movement to maneuver?

- Monitor the movement of your platoon or individual platforms to CSS locations?

- Navigate to crews requiring casualty evacuation or vehicle recovery?

- Link up with another unit?

- Control your platoon's fires (defense)?

- Select overwatch positions?

3. Have you used FBCB2 to consolidate range cards prepared by subordinates? If not, why?

4. Do you use your FBCB2 during the planning process? If so, how?

5. Do you think you have progressed through different levels of FBCB2 proficiency, such that there were insights you gained or skills you acquired that gave you a greater ability to use digital systems? If so, what were these skills and insights, and what new capability did you gain? 
6. Where there any problems in operating FBCB2 or in the application of information that you encountered early on that you have now mastered? What were these problems?

7. Do you have unit SOPs for filter settings and file management?

8. What PCl's do you perform on digital systems? 


\section{Company Commanders}

1. Do you use FBCB2 to predict where, when, and how you will likely engage the enemy?

a. If so, what tools, overlays, etc. do you use?

- FBCB2 terrain analysis tool

- Enemy situation template

- Overlays provided by higher headquarters showing enemy observation fans, range fans, etc.

- Obstacle overlays

- Information provided by engineers regarding trafficability, weather, etc.

- Others?

b. What decisions does FBCB2 assist you in making (some considerations below)?

- Pick a route or routes offering cover and concealment

- Test route selected

- Decide where smoke or supporting fires might be needed

- Decide where to change formations and movement techniques prior to contact

- Selection of overwatch positions

- Others?

c. Circle below information that is communicated and indicate to whom and how.

- Route and fire support requirements given to battalion

- Commander verbally or via FBCB2

- Every recipient on battalion command net

- Every recipient on company net

- Location where visual contact is likely to be made

- Commander verbally or via FBCB2

- Every recipient on battalion command net

- Every recipient on company net

- Overwatch positions

- Commander verbally or via FBCB2

- Every recipient on battalion command net

- Every recipient on company net

- Others?

2. What digital planning products do you look at during the planning and preparation phases to make sure you are ready to perform your mission? What do you look for with each product?

- Maneuver plan

- Fire support plan

- CSS plan

- IPB products 
3. If you saw a problem with a plan in terms of information gaps, what would you do?

4. Do you look at digital planning products to see if there have been any changes? If so, which ones?

5. How do you know when digital planning products are available for the first time and when they have been updated?

6. What naming conventions do you use in saving orders, overlays and messages?

7. How does your company CP manage digital orders/naming conventions/filing? Is there a unit SOP governing this?

8. How do you achieve a Common Operating Picture for your company?

9. What rules of thumb do you use for setting your FBCB2 filters? Is there a unit SOP governing this?

10. Have you used FBCB2 to plan/distribute direct and indirect fire plans? Consolidate platoon fire plans?

11. Have you ever used FBCB2 SA to:

- Monitor your unit's transition from movement to maneuver before contact?

- Conduct a tactical movement under limited visibility situations?

- Check the actions of platoons?

- Move to a breach point or monitor movement of your platoons to a breach point?

- Link up with another unit?

- Make sure your platoons stay away from threat situations (obstacles, contaminated areas, firesacks)?

- Make sure you are not about to cross paths with another company team?

- Monitor movement of platoons or platforms to CSS locations?

- Monitor casualty evacuation and vehicle recovery? (If not, have you participated in exercises where vehicle recovery and casualty evac were played?)

12. Have you had any problems keeping track of SA data throughout the mission planning, preparation and execution process (if so, what problems)? How did you know how to solve the problem?

13. What PCl's do you perform on digital systems? 
14. Do you think you have progressed through different levels of FBCB2 proficiency, such that there were insights you gained or skills you acquired that gave you a greater ability to use digital systems? If so, what were these skills and insights, and what new capability did you gain?

15. Were there any problems in operating FBCB2 or in applying information that you encountered early on that you have now overcome? What were these problems? What enabled you to master these skills? 


\section{Battalion Staff}

1. Do you think you have progressed through different levels of digital proficiency, such that there were insights you gained or skills you acquired that gave you a greater ability to use digital systems? If so, what were these skills and insights, and what new capability did you gain?

2. Were there any problems in operating digital systems or applying their information that you encountered early on that you have now mastered? What were these problems? (i.e., What problems will a new member of the staff have?)

3. As you gained experienced using digital systems were there any activities that you had been performing in an analog fashion that you gradually shifted over to digital? If so, what were they?

4. Given that digitization provides the capability to speed up the planning process and disseminate plans quicker, do you get feedback from other BOSs in time to make changes?

5. Do you have trouble tracking changes in the various plans and overlays? How do you resolve this?

6. In an actual combat situation, are there any types of feedback about your unit's tactical performance that you would like to have available in time to take immediate corrective action? This feedback can cover planning, preparation, execution or reconstitution/recovery.

7. How do you construct the common operating picture? What problems (if any) are frequently encountered?

8. Do you have digital SOPs to govern operations and TTPs involving digital C2 systems? (e.g., How to make the digital capabilities a combat multiplier.) 


\section{Battalion Commander}

1. Do you think you have progressed through different levels of digital proficiency, such that there were insights you gained or skills you acquired that gave you a greater ability to use digital systems? If so, what were these skills and insights, and what new capability did you gain?

2. What are the problems a new battalion commander is likely to encounter operating in the digital environment? (e.g., What problems did you have that tended to disappear with experience?)

3. What gradual changes have you noticed in the ability of your company commanders to exploit the capabilities of digitization? Have these changes resulted in performance benefits? If so, how?

4. What gradual changes have you noticed in the ability of your staff to exploit the capabilities of digitization? Have these changes resulted in performance benefits? If so, how?

5. In an actual combat situation, are there any types of feedback about your unit's tactical performance that you would like to have available in time to take immediate corrective action? This feedback can cover planning, preparation, execution or reconstitution/ recovery. 


\section{Brigade Commander}

1. Do you think you have progressed through different levels of digital proficiency, such that there were insights you gained or skills you acquired that gave you a greater ability to use digital systems? If so, what were these skills and insights, and what new capability did you gain?

2. What gradual changes have you noticed in the ability of your staff to exploit the capabilities of digitization? Have these changes resulted in performance benefits? If so, how?

3. In an actual combat situation, are there any types of feedback about your unit's tactical performance that you would like to have available in time to take immediate corrective action? This feedback can cover planning, preparation, execution or reconstitution/ recovery. 


\section{Brigade Staff}

1. Do you think you have progressed through different levels of digital proficiency, such that there were insights you gained or skills you acquired that gave you a greater ability to use digital systems? If so, what were these skills and insights, and what new capability did you gain?

2. Given that digitization provides the capability to put draft plans out in front of people earlier, are you getting feedback from other BOSs in time to make changes? If not, why?

3. Do you have trouble tracking changes in the various plans? How do you overcome this?

4. In an actual combat situation, are there any types of feedback about your unit's tactical performance that you would like to have available in time to take immediate corrective action? This feedback can cover planning, preparation, execution and reconstitution/ recovery.

5. Do you have digital SOPs to govern operations and TTPs involving digital $\mathrm{C} 2$ systems? (e.g., How to make the digital capabilities a combat multiplier.) 



\section{APPENDIX B}

\section{List of Acronyms and Abbreviations}

$1 C D$

4ID

AAR

ABCS

AFATDS

ARI

ASAS

ATCCS

BCT

BCTC

BFA

BLUFOR

$\mathrm{Bn}$

BOS

C4I

CCIR

CCTT

CFF

CLOS

$\mathrm{CM}$

Co

COA

COMSEC

COP

CSMA

CSS

CSSCS

CTIL

CTCP

DTG

EBC

EPLRS

FBCB2

FBCB2-TFV

FDD

FFIR

FIPR

FM

FM

FSR

FTX 1st Cavalry Division

$4^{\text {th }}$ Infantry Division

After Action Review

Army Battle Command System

Advanced Field Artillery Tactical Data System

U. S. Army Research Institute

All Source Analysis System

Army Tactical Command and Control System

Brigade Combat Team

Battle Command Training Center

Battle Functional Areas

Blue Forces

Battalion

Battlefield Operating System

Command, Control, Communications, Computers, And Intelligence

Commander's Critical Information Requirement

Close Combat Tactical Trainer

Call For Fire

Circular Line Of Sight

Center Of Mass

Company

Course Of Action

Communications Security

Common Operational Picture

Carrier Sense Multiple Access

Combat Service Support

Combat Service Support Control System

Commander's Tracked Items List

Combat Trains Command Post

Date Time Group

Embedded Battle Command

Enhanced Position Location Reporting System

Force XXI Battle Command Brigade And Below

Fbcb2 Training Feedback Variables [Project]

First Digitized Division

Friendly Forces Information Requirements

Flash-Immediate-Priority-Routine

Field Manual

Frequency Modulation

Field Service Representative

Field Training Exercise 


$\begin{array}{ll}\text { GPS } & \text { Global Positioning System } \\ \text { IAW } & \text { In Accordance With } \\ \text { INC } & \text { Internet Controller } \\ \text { LCN } & \text { Logical Channel Network } \\ \text { LD } & \text { Line Of Departure } \\ \text { LOGSTAT } & \text { Logistics Status [Report] } \\ \text { LOS } & \text { Line Of Sight } \\ \text { LP/OP } & \text { Listening Post/Observation Post } \\ \text { MDL } & \text { Mission Data Loader } \\ \text { MEDEVAC } & \text { Medical Evacuation } \\ \text { MSE } & \text { Mobile Subscriber Equipment } \\ \text { MSTF } & \text { Mission Support Training Facility } \\ \text { MTP } & \text { Mission Training Plan } \\ \text { NBC } & \text { Nuclear, Biological, Chemical } \\ \text { NCO } & \text { Non-Commissioned Officer } \\ \text { NFZ/NFA/RFL } & \text { No Fire Zone/No Fire Area/Restrictive Fire Line } \\ \text { NTC } & \text { National Training Center } \\ \text { NTDR } & \text { Near Term Digital Radio } \\ \text { OC } & \text { Observer/Controller } \\ \text { OP } & \text { Observation Post } \\ \text { OPORD } & \text { Operation Order } \\ \text { PCC/PCI } & \text { Pre-Combat Checks/Pre-Combat Inspections } \\ \text { PERSTAT } & \text { Personnel Status [Report] } \\ \text { PLGR } & \text { Precision Lightweight Gps Receiver } \\ \text { PIt } & \text { Platoon } \\ \text { PMCS } & \text { Preventive Maintenance Checks And Services } \\ \text { SA } & \text { Situational Awareness } \\ \text { SBCT } & \text { Stryker Brigade Combat Team } \\ \text { SIMEX } & \text { Simulation Exercise } \\ \text { SINCGARS } & \text { Single Channel Ground And Airborne Radio System } \\ \text { SME } & \text { Subject Matter Expert } \\ \text { SOP } & \text { Standing Operating Procedure } \\ \text { SSRU } & \text { Simulator Systems Research Unit } \\ \text { SU } & \text { Situational Understanding } \\ \text { TACSOP } & \text { Tactical SOP } \\ \text { TF } & \text { Task Force } \\ \text { TI } & \text { Tactical Internet } \\ \text { TIM } & \text { Tactical Internet Manager } \\ \text { TOC } & \text { Tactical Operations Center } \\ \text { TRADOC } & \text { U.S. Army Training And Doctrine Command } \\ \text { TTP } & \text { Tactics, Techniques, And Procedures } \\ \text { UAV } & \text { Unmanned aerial vehicle } \\ \text { UTR } & \text { Unit Task Reorganization } \\ \text { WIN-T } & \text { Warfighter Information Network-Terrestrial } \\ & \\ & \end{array}$

